Florida International University FIU Digital Commons

3-30-2006

\title{
Supplemental instruction, study habits, and the community college student
}

Eileen Garcia

Florida International University

DOI: $10.25148 /$ etd.FI15101519

Follow this and additional works at: https://digitalcommons.fiu.edu/etd

Part of the Higher Education Commons

\section{Recommended Citation}

Garcia, Eileen, "Supplemental instruction, study habits, and the community college student" (2006). FIU Electronic Theses and Dissertations. 3871.

https://digitalcommons.fiu.edu/etd/3871

This work is brought to you for free and open access by the University Graduate School at FIU Digital Commons. It has been accepted for inclusion in FIU Electronic Theses and Dissertations by an authorized administrator of FIU Digital Commons. For more information, please contact dcc@fiu.edu. 
FLORIDA INTERNATIONAL UNIVERSITY

Miami, Florida

SUPPLEMENTAL INSTRUCTION, STUDY HABITS, AND THE COMMUNITY COLLEGE STUDENT

A dissertation submitted in partial fulfillment of the

requirements for the degree of

DOCTOR OF EDUCATION

in

HIGHER EDUCATION

by

Eileen Garcia

2006 
To: Dean Linda P. Blanton

College of Education

This dissertation, written by Eileen Garcia, and entitled Supplemental Instruction, Study Habits, and the Community College Student, having been approved in respect to style and intellectual content, is referred to you for judgment.

We have read this dissertation and recommend that it be approved.

Stephen M. Fain

George O'Brien

Janice R. Sandiford

Leonard B. Bliss, Major Professor

Date of Defense: March 30, 2006

The dissertation of Eileen Garcia is approved.

Dean Linda P. Blanton

College of Education

Interim Dean Stephan L. Mintz

University Graduate School

Florida International University, 2006 


\section{ACKNOWLEDGMENTS}

Life's greatest goals are rarely achieved without the invaluable assistance of others. I wish to take this opportunity to thank my committee members, Dr. Janice Sandiford, Dr. George O'Brien, and Dr. Stephen Fain, for their insights and encouragement. I most especially want to thank my committee chair, Dr. Leonard Bliss, and Dr. Linda Bliss, for their vast knowledge, tireless dedication, boundless energy, and unwavering support in helping me obtain this most cherished doctoral degree. Mere words truly cannot express my gratitude to them for helping me believe in myself, and for helping me understand that great things can be achieved through determination, patience, and perseverance. A special thank you as well to Professor Deborah Dibble for her kind cooperation and assistance in completing this project. Lastly, I must thank my partner Gail C. Flanagan, without whose affection, faith, generosity, and selfless support this dream would have never been realized. 


\section{ABSTRACT OF THE DISSERTATION \\ SUPPLEMENTAL INSTRUCTION, STUDY HABITS, \\ AND THE COMMUNITY COLLEGE STUDENT \\ by \\ Eileen Garcia \\ Florida International University, 2006 \\ Miami, Florida \\ Professor Leonard B. Bliss, Major Professor}

The purpose of this study was to demonstrate if the academic assistance program Supplemental Instruction (SI) facilitates the acquisition of effective study behaviors through strategies that transcend simple double-exposure to the course material. Its advocates claim it increases academic achievement using learner-centered knowledge and acquisition of effective study behaviors. SI sessions are specifically related to particular courses that students are taking. Sessions are facilitated by the SI leader who has taken the subject matter course in the past. Students review the content of the previous subject matter class using collaborative learning strategies coordinated by a SI leader. In addition, the SI leader models appropriate study behaviors in his or her interactions with the students.

An instructor at a large Florida community college who taught five classes of an Anatomy \& Physiology I course (traditionally supported by SI) was identified. Two of the classes were randomly selected to participate in SI activities, and two classes were random chosen to participate in alternate, computer-based activities that dealt with the course content, but did not include work in developing students' study behaviors. These 
treatments were carried out over the course of an entire semester. Participation was mandatory.

Data were collected on two variables. Academic achievement in anatomy and physiology content was measured both pre- and post-treatment using an instructor developed examination. Student study behaviors were measured using pre- and posttreatment administration of the Study Behavior Inventory, a valid and reliable instrument that provides scores on three categories of study behaviors: (a) Academic self-efficacy, (b) Preparation for routine academic tasks, and (c) Preparation for long range academic tasks. Measures obtained at the end of the semester of treatment revealed no significant differences between the SI and alternative treatment groups in post-treatment achievement test score and the post-treatment scores on the three study behaviors categories when adjusted for pre-treatment scores.

These results suggest that the development of appropriate study behaviors requires more time than SI, as it is now implemented, can provide. In addition, results indicate that improved academic achievement may be attained through any number of means that include repeated exposure to course material. 


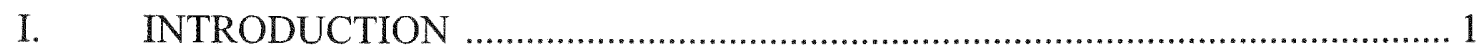

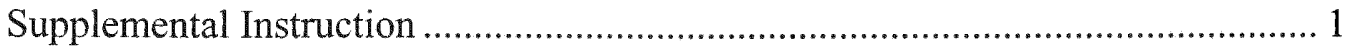

Theoretical Base of Supplemental Instruction.............................................. 2

Study Skills and Study Habits/Behaviors ................................................... 5

Studying and Academic Achievement................................................................ 8

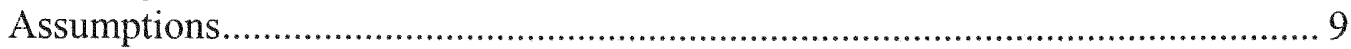

Organization of the Study ............................................................................... 10

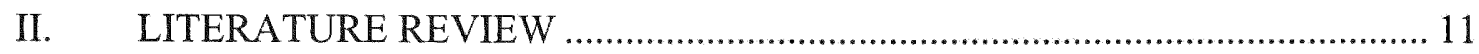

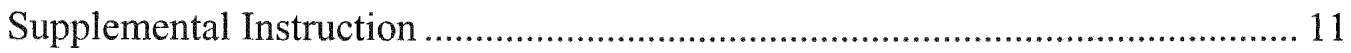

History of Supplemental Instruction......................................................... 11

Description of Supplemental Instruction ................................................... 14

Theoretical Foundations of Supplemental Instruction........................................ 18

The Nature of Constructivism................................................................ 18

Learner Centered Approaches to Education .............................................. 19

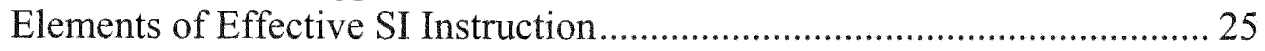

Supplemental Instruction is informed by Constructivist Ideas .....................227

Supplemental Instruction and Social and Emotional Variables.................... 32

The Role of Collaborative Learning in Supplemental Instruction................ 39

Empirical Findings on the Use of SI in Higher Education ................................. 42

SI Effects on Student Participant Achievement.......................................... 42

SI and Related Effects on Student Participants........................................... 45

Study Behaviors and Achievement ..................................................................... 49

SI's Impact on Study Behaviors - Theoretical Considerations .................. 51

SI's Impact on Study Behaviors - Empirical Evidence................................ 53

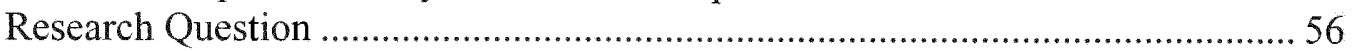

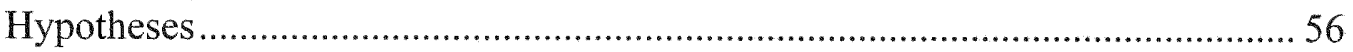

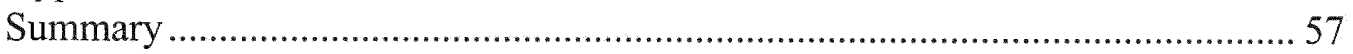

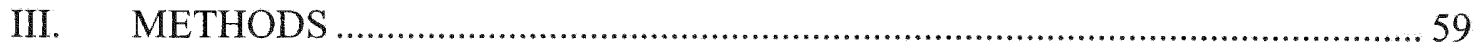

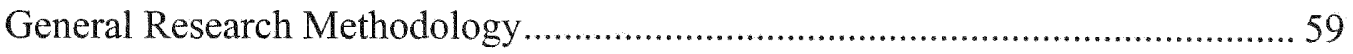

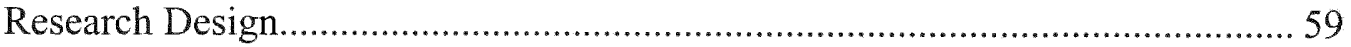

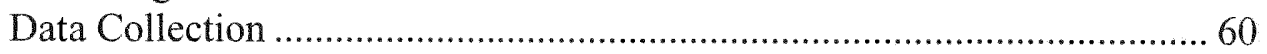

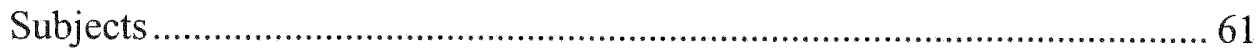

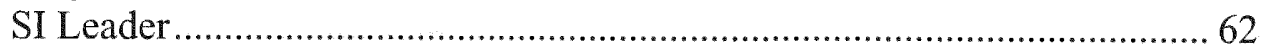

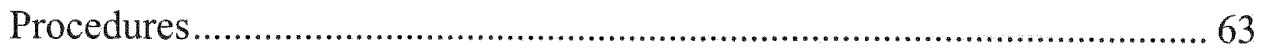

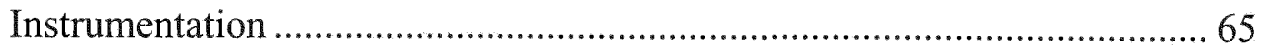

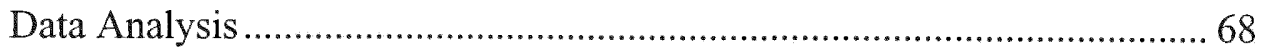

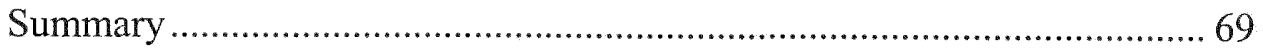




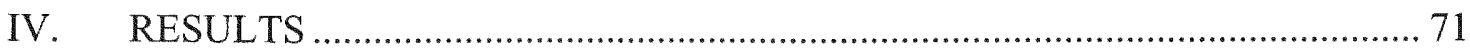

Description of the Sample................................................................................. 71

The Potential Problems of High Mortality Rates......................................... 71

Comparing the Completing and the Non-completing Participants .............. 72

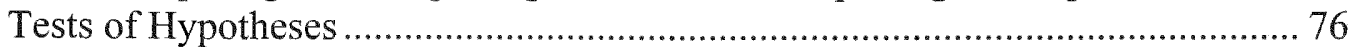

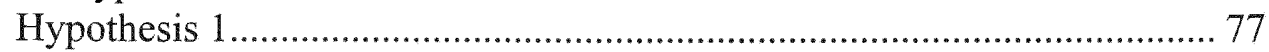

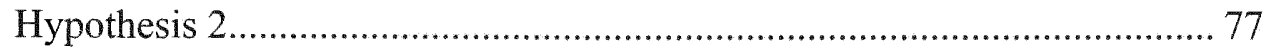

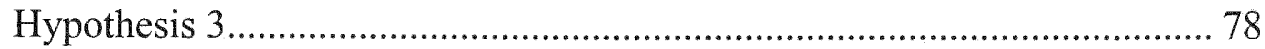

Anatomy and Physiology I Content Knowledge ....................................... 79

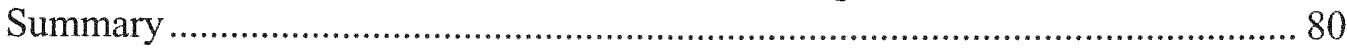

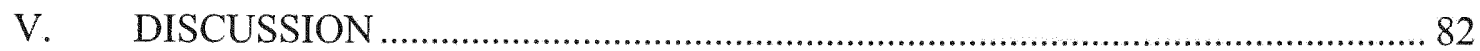

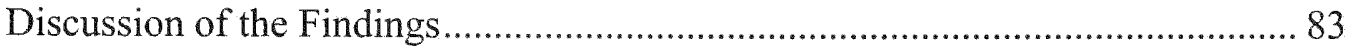

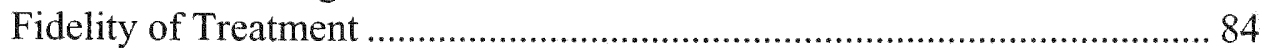

Double Exposure................................................................................ 90

Academic Characteristics of Participants ................................................ 92

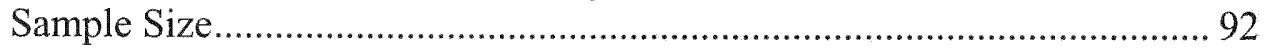

Conclusions, Implications, and Directions for Future Research.......................... 93

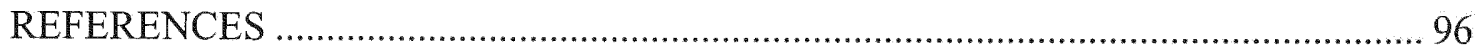

VITA 


\section{LIST OF TABLES}

TABLE

PAGE

1. Descriptive Statistics for Completers and Non-completers on the Achievement Pretest and the Pre-treatment Scores on the Study Behavior Inventory Factors.

2. Analysis of Variance for Achievement Pretest................................. 74

3. Analysis of Variance for the SBI Factor 1 Pretest.................................. 74

4. Analysis of Variance for the SBI Factor 2 Pretest................................. 75

5. Analysis of Variance for the SBI Factor 3 Pretest.................................76

6. ANCOVA for the SBI Self-Esteem Factor ................................................................

7. ANCOVA for the SBI Time Management for the Preparation for Routine, Everyday Tasks Factor.

8. ANCOVA for the SBI Time Management for the Preparation for Long Range, Unique Academic Tasks Factor .79

9. ANCOVA for Anatomy and Physiology Content Knowledge .80 


\section{CHAPTER I}

\section{INTRODUCTION}

For some considerable time, the demand for the improvement of public education has sounded from a variety of political quarters. In the years since the publication of $A$ Nation at Risk: The Imperative for Educational Reform (National Commission on Excellence in Education, 1983) and the passage of the Goals 2000: Educate America Act, educators have found themselves under pressure to serve the increasingly diverse learning requirements of American students while concurrently striving to produce higher levels of achievement.

The concern in educational circles regarding sub-standard achievement and student attrition has led educators to call for a more learner-centered approach to instruction. This approach and the various models and programs that embrace it have been recognized as addressing student diversity and also yielding encouraging results (American Psychological Association, 1995, 1997). The purposes of this study were to examine the efficacy of one such model, Supplemental Instruction, in teaching Anatomy and Physiology I to community college students and to determine the effects of Supplemental Instruction on these students' study behaviors.

\section{Supplemental Instruction}

Developed in 1973 by researchers at the University of Missouri-Kansas City, Supplemental Instruction, or SI as it is commonly called, is a post secondary academic assistance program that improves academic performance through the use of a combination of cooperative and collaborative learning strategies. The program has three closely related goals: (a) improvement of student course grades, (b) reduction of attrition 
rates in historically difficult college courses, and (c) student persistence toward graduation. The SI program targets historically difficult academic courses - those that typically have $30 \%$ or higher rate of $\mathrm{D}$ or $\mathrm{F}$ final course grades and/or withdrawals. The idea is to provide regularly scheduled, after-class, peer facilitated sessions that offer students an opportunity to discuss and process course information (Martin, Lorton, Blanc, \& Evans, 1977). Since it does not identify high-risk students but identifies high-risk classes, SI avoids the remedial stigma often attached to traditional academic assistance programs. Many studies have documented positive relationships between SI attendance and academic achievement (Burmeister, 1994; Congos, Langsarn, \& Schoeps, 1997; Kenney, 1989; Lockie \& Van Lanen, 1991; Lundeberg, 1990; Lunderberg \& Moch, 1995; Van Lanen \& Lockie, 1997).

\section{Theoretical Base of Supplemental Instruction}

Supplemental Instruction is based on sound constructivist principles. These principles represent a developmental perspective that assumes that students will learn if the proper conditions for learning are in place. The proper conditions, according to these constructivist principles, must be centered on the learner and not the subject to be learned. There are two major constructivist perspectives that are grounded in research generated in connection with the theory of cognitive development espoused by Swiss psychologist Jean Piaget (1954), and the sociocultural cognitive theory of the Russian psychologist Lev Vygotsky (1962). Piaget stated that learners actively construct their understanding of the world. Through cognitive processes individuals incorporate new information into existing knowledge and then adjust to that new information (Kuhn, Black, Keselman, \& Kaplan, 2000; Phye, 1997; Schaie, 1977; Vidal-Abarca, Martinez, \& 
Gilabert, 2000; Ward, Byrnes, \& Overton, 1990). Vygotsky also emphasized this active construction of knowledge. However, his sociocultural cognitive theory stresses the role of language and the context of social relations (Tappan, 1998), which in addition to internal cognitive processes focuses particular attention on social and cultural elements. These two major constructivist perspectives (cognitive and sociocultural) are unified in the concept that learners individually and socially construct meaning as they learn.

By incorporating these two major constructivist perspectives and their associated learner-centered principles, the SI program was developed to encourage students to become actively involved in their own learning. By the learner-centered integration of appropriate study behaviors with the review of course material, students can begin to understand and utilize the learning strategies they have only heard about from instructors and counselors.

The program of Supplemental Instruction is currently practiced in approximately 300 institutions in the United States and abroad. Continuing research on SI indicates that it is effective across a number of different disciplines and institutions, and with a variety of students. As mentioned earlier, many studies have been done to demonstrate the SI program's effectiveness in college level courses. It has also been proven effective when applied to specific populations including athletes (Martin \& Blanc, 1994), women (Lundeberg \& Moch, 1995), and minority students (Noel \& Levitz, 1982; Martin \& Arendale, 1993). Although traditionally SI has been most popular in math and science courses, it has been successfully applied in a variety of disciplines. One particular arena outside the sciences where SI is commonly and successfully adapted is in writing and composition courses (McMillin, 1983; Wolfe, 1987). One of the reasons that 
Supplemental Instruction has been successful in helping students achieve in college level courses is that it goes beyond the teaching of cognitive subject matter topics.

Supplemental Instruction has been shown to help students develop study skills and behaviors that are more easily generalized than subject matter content (Martin \& Arendale, 1993).

Traditionally, students having difficulties in academic classes were assigned academic tutors who worked with them in a one to one basis. However, research suggests that this traditional tutoring relationship does not always precipitate the transfer of necessary academic skills (Blanc, DeBuhr, \& Martin, 1983; Martin \& Arendale, 1993; Maxwell, 1990). As a result, a central responsibility of the SI leader in an SI session is to achieve the successful integration of effective study skills and behaviors with course content. The integration of these study strategies with the course content is a key difference between SI and tutoring. Supplemental Instruction is more than simply the remediation of course-related, subject matter difficulties. Its planned integration of study strategies sets SI apart from other types of academic support (Arendale, 1994).

While many researchers have demonstrated the efficacy of Supplemental Instruction (Blanc et al., 1983; Commander, Stratton, Callahan, \& Smith, 1996; Maxwell, 1998; Ramirez, 1997), recognized its value with at-risk students (Boylan, 1999; Commander et al., 1996; Hodges, 2001), and observed moderately improved study behaviors as a result of participation in the SI program (Maxwell, 1998), no study has focused on these improved study behaviors nor identified the type of student whose study behaviors and academic performance benefit the most from SI. Given that students with strong study skills and effective study behaviors regularly earn the best course grades, 
such students should consistently demonstrate these exemplary behaviors, whether or not they participate in an SI program. Conversely, those students with deficient study behaviors should demonstrate a marked improvement in both study behaviors and course grade after participation in SI, and the non-SI students with deficient study behaviors should evidence no such improvement.

A number of researchers have shown weak study strategies among students experiencing learning difficulties (Henley, Ramsey, \& Algozzine, 1996; Hoover \& Patton, 1995; Ley \& Young, 1998; Strichart, Mangrum, \& Iannuzzi, 1998; Waldron \& McLeskey, 2000). Gersten (1998) tells us that the majority of students experiencing academic difficulties are just not cognizant of the various study strategies employed by academically competent students. This is where SI comes in. Through SI's learnercentered integration of appropriate study skills and behaviors with the review of course material, it has been suggested that students can begin to understand and utilize the learning strategies regularly employed by the academically successful.

In addition to the clearly at-risk students, otherwise capable students at colleges and universities may experience academic difficulties not due to a lack of ability, but rather due to the lack of effective study behaviors. The identification of an academic assistance program that not only successfully remedies this deficiency for all students, but at the same time is of particular benefit to the at-risk student, can be of significant value to educational institutions nationwide.

Study Skills and Study Habits/Behaviors

In recent years a useful distinction has emerged that allows differentiation between a study skill and a study habit or behavior. Bliss and Mueller (1987) were 
among the first to note that the distinction lies in distinguishing between potential and actual behavior. This distinction is elaborated below.

Study skills. Study skills are generally steps or procedures such as highlighting, outlining, note-taking, summarizing, etc. that may be taught through explicit instruction (Gettinger \& Seibert, 2002). Study skills are the specific techniques that make up the study plan. Included with the examples given above are such skills as deciding what is important through the use of text signals (headings, bold words, etc.). Students can be taught to practice using such signals and learn to distinguish key concepts and main ideas (Lorch, Lorch, Ritchey, McGovern, \& Coleman, 2001). Summaries can be helpful, but students have to be shown how to summarize (Dole, Duffy, Roehler, \& Pearson, 1991). Underlining and highlighting are also advantageous but only if the students are selective, actively transforming the text into their own words, noting connections between the new material and that which is already known, and looking for organizational patterns to guide the highlighting or underlining. Note-taking allows students to focus attention during class and record ideas in their own words, thereby aiding encoding to long term memory (Kiewra, 1988).

Study skills can indeed be valuable but only if fully understood and used appropriately. With Supplemental Instruction the SI leader acts as the "model student" and demonstrates how successful students think about and process course content. They facilitate a process of collaborative learning, a critical strategy since it helps students to empower themselves rather than remain dependent as they likely would with traditional tutoring. SI provides numerous opportunities to address study skills within the content of the course. Past research has shown that teaching study skills separate from subject 
content has a negligible impact on the students' academic performance (Bender, 2001;

Dimon, 1998; King \& Stahl, 1985). Although students can be taught complex notetaking and text-reading strategies, these skills may not be utilized in subsequent courses. In addition, different classes will most likely require a different approach to note-taking, and texts are organized differently and used differently depending upon the subject matter (Arendale, 1998).

Study habits/behaviors. Study behaviors, by contrast, constitute the overall approach itself: representing the student's concept of how to accomplish learning goals and the specific actions taken (Jones, Slate, Perez \& Marini, 1996). A positive example might be a student first deciding to study every night and then employing a combination of mnemonics for memorizing key terms, skimming text material to ascertain organizational patterns and jotting down answers to possible exam questions (Woolfolk, 2004); an optimum strategic combination of skill and volition. The elements of study behaviors include, for example, study time planning, frequency of studying, duration of studying, and choice and application of appropriate study skills. However, not all study behaviors exhibit effective learning strategies. While there is no doubt that effective study behaviors embody effective study skills, study behaviors can also be ineffective and may include procrastination and deliberate inaction (Bailey \& Onwuegbuzie, 2002).

It has been assumed that good studying is the same thing as the correct use of study skills, yet as Paris and Winograd (1990) pointed out, rote application of a study skill does not equate to effective studying. Rather, the application of a sound study behaviors, like those integral to SI, enhance the effectiveness of study skills and represent one's comprehensive approach to planning and evaluating one's own study behavior. 
Even though such behaviors require the knowledge of study skills, the primary focus in fostering good study behaviors is learning how to study, deciding about the use of various study skills, and being responsible for one's own learning (Gettinger \& Seibert, 2002).

SI leaders are trained in proactive learning and effective study strategies and attend all course lectures, take notes, and read all assigned materials. These SI leaders subsequently conduct three or more out-of-class SI sessions per week during which they integrate the specifics of "how to learn" with "what to learn" (Blanc et al., 1983). SI leaders model suitable questioning and reasoning, and aspects of effective thinking and action strategies to be internalized by the students and subsequently incorporated into their individual and group study skills and behaviors (Arendale, 1998). This is an especially important feature of SI since there is substantial evidence linking higher levels of achievement with more advanced study skills. King (1990) found that college students who employed summarization and self-questioning study skills exhibited higher levels of achievement than students who employed other types of study strategies.

To reiterate, SI leaders are to integrate effective study skills and behaviors with course content. This planned integration of study strategies distinguishes SI from other types of academic support (Arendale, 1994). The exposure to different perspectives and learning strategies teaches the learner how to better acquire, manipulate, and apply new knowledge. This is a common goal of instructors and a core concept of SI.

Studying and Academic Achievement

Research has consistently documented the positive relationship between study behaviors and academic success (Agnew, Slate, Jones, \& Agnew, 1993; Elliott, Godshall, Shrout, \& Witty, 1990; Irandoust, \& Karlsson, 2002; Jones, Green, Mahan, \& Slate, 
1993; Jones, Slate, \& Marini, 1995; Jones, Slate, Perez et al., 1996; Kachgal, Hansen, \& Nutter, 2001; Lammers, Onwuegbuzie, \& Slate, 2001; Onwuegbuzie, Slate, \& Schwartz, 2001; Stanley, Slate, \& Jones, 1999). Research has also indicated that only 51\% (Agnew et al., 1993) to $61 \%$ (Slate, Jones, \& Harlan, 1998) of suitable study behaviors are utilized by undergraduate level students. Different from incidental learning, studying requires a student's conscious effort. Even though students are expected to exhibit appropriate study behaviors when preparing for exams, the simple fact is that typically very little explicit instruction is ever provided (Gettinger \& Seibert, 2002).

The literature provides enough empirical and anecdotal evidence to suggest that student study activities need improvement, even at the college level (Thomas, Bol, \& Warkentin, 1991; Wade, Trathen, \& Schraw, 1990; Wratcher, 1991). An academic assistance program that can be shown to increase the use of appropriate study behaviors and subsequently help students to achieve academic success would therefore be invaluable.

The significant monetary costs associated with the implementation of academic assistance programs makes the identification of one that addresses a common academic need in both traditional and at-risk student populations of particular import and value.

\section{Assumptions}

The following assumptions are held by the researcher of this study:

- Course instructors are supportive of the SI model.

- SI leaders are well trained in the implementation of the SI model.

- The students involved in this study are highly motivated as they have chosen career paths requiring successful completion of this course. 
- The culture of the institution is strongly supportive of successful implementation of the SI model.

To summarize then, the efficacy of Supplemental Instruction in improving academic achievement has been well documented. Although the SI program focuses on imparting successful study skills and behaviors, no study to date has adequately demonstrated this. Therefore, the purpose of this study is to show if participation in Supplemental Instruction improves academic achievement as well as study behaviors, as demonstrated through the use of specific measures of both content mastery and study behaviors.

\section{Organization of the Study}

The remaining sections of this research report are divided into the following chapters. In Chapter 2, the author examines the relevant literature with respect to the efficacy and application of the SI program and its impact on study behaviors. In addition, the next chapter explores the importance of study skills and behaviors to academic success. Chapter 3 discusses the research design and methods used in the study. Chapter 4 presents the findings, analysis, and evaluation of the data, and Chapter 5 provides conclusions drawn from the results and recommendations for practice and further study. 


\section{CHAPTER II}

\section{LITERATURE REVIEW}

In this chapter the researcher further clarifies the notion of Supplemental Instruction and presents the theoretical base upon which it rests in terms of its intended efficacy and its effects on study behaviors. In addition, the researcher develops the theoretical base that connects study behaviors with academic achievement.

Traditionally, institutions of higher education have set up tutoring programs for students in need of help in specific classes or on specific academic skills. These tutoring programs have tended to be expensive and have often provided less than satisfactory results, often because they dealt solely with specific course content and failed to respond to basic, general problems students had in preparing for and carrying out academic tasks. Supplemental Instruction is a strategy for augmenting instruction in such a way that student participants can work improving their study skills and behaviors in the context of working to achieve specific class-related cognitive objectives. This strategy is described and reviewed in the sections that follow.

\section{Supplemental Instruction}

In response to the concerns over student attrition, a number of academic assistance programs have evolved in recent years that emphasize self-regulated learning, and focus on the development of learning strategies (Simpson, Hynd, \& Nist, 1997). One such rapidly growing program is Supplemental Instruction (SI).

\section{History of Supplemental Instruction}

In 1973, Deanna C. Martin developed the first program of Supplemental Instruction in a pre-medical program for undergraduates at the University of Missouri- 
Kansas City (UMKC). One of the major problems SI sought to address was the especially high attrition rate among minority and disadvantaged students. At the outset, the program developers decided it would not be appropriate to follow the traditional medical model of academic assistance programs. This was largely because in that particular model, an individual is identified as needing professional assistance on the basis of: (a) prior history and diagnostic testing, (b) self-referral in response to perceived symptoms, or (c) referral by another professional in response to observed symptoms. Despite the fact that tutorial services in the medical model held the most prominent position in the academic environment, the institution at which SI was conceived simply did not fit into this model (Martin \& Arendale, 1993).

To begin with, the traditional medical model dictates that entering students must be quickly identified to allow key personnel to establish contact with at-risk students. At UMKC, student registration could take place up to the first day of classes, while prior transcripts and test score data needed only to be submitted at some point before the start of the following semester. Secondly, the SI program's developer, among others, took exception to the notion that prior performance and/or standardized testing is sufficiently valid as a predictor of who will, or will not be at risk. In fact, as many as half the students labeled potentially "at risk" based on prior scores achieve academic success without intervention, while a similar number of those not so labeled have proven to be unsuccessful (Martin \& Arendale, 1993). Several studies have indeed shown that analysis of high school grades and standardized college entrance examinations fail to identify all students destined to leave college for academic reasons (Blanc et al., 1983; Christie \& Dinham, 1991; Tinto, 1993). Also, providing assistance only to those who are 
symptomatic or exhibit a predisposition is not an effective way to address attrition (Martin \& Arendale, 1993). Earlier research suggested that treatment should be more generalized, and that it should address the problem at or near its source - that source being the disparity between the instruction level and the level of student preparation (Martin et al., 1977).

Martin and Arendale (1993) also pointed out that timely identification of at-risk students is problematic in the traditional model. Faculty members, having the ability to refer students for remediation, are most often unable to make such a referral until after they grade the first course examination. The students referred at this point, after a difficult start, are put in the position of having to try to catch up with the class. Not surprisingly, the rate of student attrition is greatest during the first 6 weeks of courses (when the students realize they are falling behind) or after receiving a disappointing grade on the first exam (Blanc et al., 1983). Sadly, students who are at risk rarely follow faculty recommendations for obtaining extra help. Student perceptions that tutorial help can actually increase the academic burden may be at the heart of this reluctance (Martin \& Arendale, 1993). In addition, at-risk students routinely wait far too long to self-refer. For whatever reason, (fear, denial, pride, ignorance, arrogance, etc.) the students who are in the most need of assistance are those least likely to ask for it (Somers, 1988).

With SI, service delivery begins on the first day of class, making the support program more proactive than reactive. Also, the presence of more capable students in support sessions removes the stigma of remediation, encouraging the participation of the less capable students. In addition, the fact that SI is voluntary calms those students who are fearful of increasing their academic burden. This combination of voluntary 
participation, early intervention, and proactive support distinguishes the SI model from the traditional medical model of symptom diagnosis and subsequent prescribed treatment (Martin \& Arendale, 1993).

After deciding upon this necessary departure from the medical model, the SI program was then conceived and created as a form of academic assistance for students enrolled in particularly difficult pre-med courses, and in recognition of its effectiveness in that specific setting, it was further extended throughout the institution. In 1981, after a rigorous review process, Supplemental Instruction became one of the few post-secondary programs to be designated by the U.S. Department of Education as an Exemplary Educational Program.

\section{Description of Supplemental Instruction}

This academic assistance program works to reduce student attrition by increasing student success in historically difficult gatekeeper courses. This is accomplished by providing regularly scheduled, after-class, peer facilitated sessions where students may interact while working with course content. SI avoids the remedial stigma often attached to traditional academic assistance programs through concentrating on high-risk classes rather than on individual high-risk students.

SI sessions are open to all students in the targeted course; hence the prescreening of students is unnecessary. Also, the attendance at SI sessions is intended to be voluntary. The program is designed to enable students to master course content while they develop and integrate effective learning and study strategies (e.g., note-taking, organization, test preparation). Since the SI sessions are scheduled to begin the first week of each academic term, the program provides academic assistance during the 
critical, first 6 weeks of class before many students face their first major examination. Researchers have demonstrated that enrollment attrition is highest during this period (Blanc et al., 1983; Noel, Levitz, \& Saluri, 1985).

Those traditionally difficult or "high-risk" courses often share the following characteristics: extensive weekly readings from both difficult textbooks and secondary library reference works, and less frequent examinations that focus on higher cognitive levels of Bloom's taxonomy. Additional characteristics are voluntary and unrecorded class attendance and sizeable classes where each student has little opportunity for interaction with the professor or fellow students. In order to provide assistance early in the academic experience, SI is frequently attached to traditionally difficult, high-risk courses that serve first and second year students (Arendale, 1994). It is understood and accepted that designating a course "high-risk" makes no prejudicial comment about the professor or the students, but rather is a numerical calculation that indicates that a sizeable number of students have difficulty in meeting academic requirements for that class. Rather than trying to blame the students or the professor, the high-risk designation recognizes that additional academic support will be needed for students to raise their level of academic performance to meet the level deemed appropriate by the course instructor.

The key persons involved with SI on each campus are the SI leaders, the SI supervisor, and the course instructor. Each of these key people has a crucial role in creating the environment that allows the SI program to flourish.

The SI leader. The SI leader, whose contribution can make the program a success or a failure, is perhaps the most important member of this triad. By definition the SI 
leader is a student who has successfully completed the targeted class, or a comparable course, with a grade of B or better. It is considered ideal if these students have taken the course from the same instructor for whom they are now providing assistance. SI leaders are trained in proactive learning and study strategies and operate as a "model student" attending all course lectures, taking notes, and reading all assigned materials.

The role of the leader is to provide structure to the study session, not to redeliver the lecture or introduce new material. The SI leaders act as "model students" and demonstrate how successful students think about and process course content. They facilitate a process of collaborative learning, a critical strategy since it helps students to empower themselves rather than remain dependent as they likely would with traditional tutoring. Past research suggests that tutoring relationships do not always promote transfer of needed academic skills (Blanc et al., 1983; Martin \& Arendale, 1993; Maxwell, 1990). Therefore, a central responsibility of the SI leader is to integrate effective study skills and behaviors with course content. The integration of these study skills and behaviors with the course content is a key difference between SI and other forms of collaborative learning. It is not just that students are collaborating; rather it is the planned integration and practice of effective study skills and behaviors that is the distinguishing feature of Supplemental Instruction (Arendale, 1994).

The SI supervisor. The second key person, the SI supervisor, is an on-site professional staff person who implements the SI program and supervises the SI leaders. The supervisor is responsible for identifying targeted courses, garnering faculty support, selecting and training SI leaders, and monitoring and evaluating the program.

Supervisors routinely meet with SI leaders once or twice weekly during the term as a 
group, or individually. Most supervisors of SI programs have formal meetings with all the SI leaders together at least three times during the term for follow-up and situational problem solving.

The SI faculty member. The third key person in implementing SI is the faculty member who teaches the targeted course for which the SI is offered. Faculty members conduct screening of SI leaders for content competency. SI leaders are encouraged to try to meet weekly with SI course faculty members (during their office hours) to discuss the planning and outcome of SI session activities. It is important to mention here that faculty cooperation is an essential ingredient of the SI model.

Consequently, SI is only used in classes where professors both understand and support the concept. Participating faculty members are free to choose their level of involvement with the SI leaders and the program supervisor. Some faculty members enjoy meeting with the SI leader to plan for SI sessions. Many other involved faculty also request that the SI leader provide anonymous feedback from students concerning difficulties they may have encountered during class lectures or with the reading materials. On the other hand, some faculty members either do not have or choose not to devote this additional time to the program. Regardless, the SI program staff makes every effort to be totally supportive of the professor. The only restrictions placed on SI leaders are that they may not share the contents of the SI session attendance sheets nor help create or grade course examinations. The philosophical and theoretical basis that determine the activities of students and staff in programs of supplemental instruction are discussed below. 


\section{Theoretical Foundations of Supplemental Instruction}

The notion of supplemental instruction is rooted in constructivism. The concepts within constructivism, which itself embodies social and cognitive developmental perspectives, have relevance to the educational process as applied to both the mechanisms of learning and the very nature of knowledge. While this idea is not new to education, there is a burgeoning and broad acceptance of the core philosophy, which has been strongly supported by extensive research in cognitive psychology (Chen, 2002). The Nature of Constructivism

As indicated in Chapter 1, much of this research has been generated in connection with the theory of cognitive development espoused by Swiss psychologist Jean Piaget (1954) in conjunction with the sociocultural cognitive theory of Russian psychologist Lev Vygotsky. Both emphasized the active construction of knowledge. Research based upon these foundational development theories gave rise to the popular view that knowledge is both situated and collaborative (Chavajay \& Rogoff, 2002; Greeno, Collins, \& Resnick, 1996; Kozulin \& Presseisen, 1995; Toma \& Rogoff, 1997).

Constructivists' core concept is that learners individually and socially construct meaning as they learn. Simply put, the construction of meaning is learning. The implications of this view are that (a) we as educators must shift focus from the subject material to the learner, and (b) we must accept the notion that knowledge is not independent of the meaning the learner constructs. Accepting this theory is to follow the lead of Piaget and Vygotsky, among others and to accept the notion that to organize the world in a rational way and then spoon-feed it to the learner does nothing to facilitate the individual construction of meaning. According to constructivist theory, to facilitate the 
individual construction of meaning the central precepts of constructivism must be acknowledged and observed.

According to Chen (2002) some of the basic precepts of constructivism are as follows:

1. Learning is not passive but must involve the learner as an active process.

2. Learners can learn to learn. While constructing meaning, systems of meaning are also constructed which facilitate recognition of similar patterns.

3. The construction of meaning is a mental process, so learning must engage the mind.

4. Learning and language are connected. Many people talk as they learn.

5. Learning has a social component. Conversation aids the acquisition of knowledge.

6. Learning is not isolated but contextual.

7. Knowledge is built on prior knowledge and relative to the status of the learner.

8. Learning takes time and requires repetition and manipulation of ideas.

9. Motivation is essential to learning. Involvement facilitates an understanding of how knowledge can be used.

To summarize, constructivism dictates that learning is not about understanding the true nature of the world but rather about trying to attach personal and social meaning and structure to a vast, incessant, and intimidating barrage of sensory data (Chen, 2002). Learner Centered Approaches to Education

It is, therefore, not surprising that learner-centered principles are evident in many of the outstanding programs currently employed in the educational system. Some have 
adopted the collaborative and active learning approach of Johnson and Johnson (1989) as a vehicle to create the social context for learner-centered education (Thompson, Licklider, \& Jungst, 2003). The process of discovering what the student is thinking, providing opportunities for the student to carefully inspect and amend possible misconceptions, and providing an environment that invites the student to expand thinking and construct new knowledge is heightened by the student's active involvement and participation in structured and genuine collaborative exercises (see for example, Johnson \& Johnson, 1989; King, 2002; Stage, Mullen, Kinzie, \& Simmons, 1998; Thompson et al., 2003). In addition to enhancing student learning, these approaches have also been shown to increase retention (Bracey, 1994; Gardiner, 1994; Svinicki, 1991; van Boxtel, van der Linden, \& Kanselaar, 2000). Learner-centered principles incorporate contributions from a wide body of research in multiple disciplines; among them clinical, social, organizational and school psychology, as well as education, sociology, philosophy and anthropology. The incorporation of these principles as well as a dynamic system to embrace them is recognized as critical elements in the future of instruction.

With the advent of learner-centered principles, several new areas of emphasis have been identified in higher education. The first of these regards the central focus of education. The shift in focus from the teacher-centered to learner-centered instruction model puts the emphasis on the effectiveness of the transmission process rather than the deliverer of the information. The second area of emphasis concerns measuring the effectiveness of education. The learner-centered model puts emphasis on content mastery, demonstration of knowledge and the use of continuous classroom assessment (formal and informal) to provide students and educators alike with feedback on learning effectiveness. 
The third area emphasizes the identification and understanding of precisely who the students are, as well as bringing about a change in thinking on the part of educators about themselves and the students they teach.

Related to this new emphasis, in 1997 the American Psychological Association (APA) published a detailed list of 12 learner-centered principles designed to target students' academic, personal, and sociocultural development. Developed by the APA Task Force on Psychology in Education and grounded in developmental theory and extensive research, these learner-centered principles (LCPs) provide educators, counselors, and administrators with useful guidelines for making education relevant, engrossing, and purposeful for all learners (Sink, 2002).

Barbara McCombs was the co-chair of the task force and primary author of the 12 principles deemed central to the learner-centered process. The task force recommended that educators consider the substantive content of these principles as well as the learning process itself. Organized into major factors, the principles were presented under the headings meta-cognitive, affective, developmental, personal and social, and lastly, individual differences (APA, 1997).

Meta-cognitive principles. Meta-cognitive principles include the nature of the learning process, the goals of the learning process, the construction of knowledge, and the realm of higher-order thinking strategies. Viewed as a natural and active process, learning is recognized as having intrinsic and social elements. The natural desire to learn is mediated by goals that have personal relevance and therefore can provide for the assumption of personal responsibility. Self-directed knowledge acquisition in this environment actively involves the learner in the learning process. The learner creates and 
constructs meanings and interpretations based on prior knowledge and beliefs, frequently through social interaction with others (APA, 1997).

The goal of the learning process involves the creation of personally relevant and sensible explanations of knowledge regardless of how well or poorly the knowledge may be communicated or understood. Intrinsic understandings are created that do not necessarily agree with external objectives but can be refined by discussion with others and revised with the introduction of additional information. The construction of knowledge therefore reflects the unique background of the learner and can vary widely among individuals. In consideration of this reality, the goal of education must be to assist groups of learners to form shared understandings of basic skills and knowledge, which will ultimately yield desirable outcomes. The teacher or group leader can facilitate this process by creating opportunities for the learner to acquire successful strategies for the construction, organization, retention, and effective manipulation of knowledge. Employing the mechanisms of higher-order or executive processes, where the learner is cognizant of an internal locus of control, requires an environment where the learner's individual goals, interests and values are recognized and provided for. Recognition of one's own control over the learning process provides for creative and critical thinking and lays the groundwork for the attainment of proficiency (APA, 1997).

Affective factors. The affective factors in the learner-centered principles deal with motivational issues. Internal expectations, feelings, and beliefs can either support or undermine learning. Acknowledging the well-established relationship between thought, mood, and behavior is critical in understanding the importance of creating a positive learning environment. The quantity, quality, and retention of learned information is 
directly impacted by beliefs regarding self-efficacy, relevance of personal goals and values, individual expectations, state of mind and related intrinsic motivations. Natural curiosity can be compromised by the presence of negative thoughts and emotions. The onus is on the educator to stimulate and preserve this natural curiosity through techniques of interpersonal support and the imparting of successful strategies to achieve selfdiscipline, and eliminate or greatly alleviate the effects of low self-esteem and/or external pressures. In environments that learners view as personally significant or relevant, flexibility, creativity, and insight flourish. Along these lines, experiential learning settings that provide for flexibility in the course of learning, to complement interests and personal insights, often achieve amazing results. Active involvement and elements of personal control give rise to utilization of executive thinking processes and unlocks creativity. In addition, curiosity is especially aroused when the learner can tackle subjects of complexity and uniqueness while in close and cooperative interaction with others (APA, 1997).

Developmental factors. Developmental factors encompass the unique genetic and environmental elements instrumental in the individual's progress through various physical, emotional, intellectual, and social stages. Although individuals achieve optimal learning when presented with material appropriate to their developmental stage, stimulation must also be considered. Researchers have demonstrated that individuals can also learn through interaction with others at differing levels of development or achievement. Undue emphasis on developmental readiness however, can preclude higher levels of achievement, so while recognition of developmental differences is important, excessive reliance on categorization may act to impede individual progress (Fischer, 
1999; Lyle, 2000; Piaget \& Inhelder, 1969; Von Glaserfeld \& Kelley, 1982; Vygotsky, 1978).

Personal and social factors. Social and cultural diversity has been shown to facilitate learning. In the constructivist model of instruction design, the focus is on the social, inter-subjective nature of knowledge construction (Rapmund \& Moore, 2002), and learning is placed in the hands of the learner (Vermunt, 1998). As per Becvar and Becvar (1996), the focus is more on the process than the content, and therefore not on the task itself but rather on how the students do best what they desire to accomplish. To this dynamic context each learner brings his or her unique background, ideas, stories, and personal and interpersonal skills, and then the facilitator works with all the learner's contributions (Au, 1998). Since diversity implies the need to respect cultural differences, it is important for the facilitator to understand and accept that people from diverse cultural backgrounds may contribute very different perspectives and have very different ways of approaching the same task or concept. When the facilitator embraces this concept, a diversity of solutions becomes possible, which enhances and enriches the learning experience for all (Rapmund \& Moore, 2002). Consequently, learning environments that provide for interaction between individuals of different ages and from different racial, ethnic, or family backgrounds, advance the development of social competence and morals, and promote the development of multiple and varied perspectives. Elements of social acceptance are also involved in the learning process.

When individuals are engaged with others in caring, mutually respectful and accepting relationships, the resulting healthy self-image facilitates knowledge acquisition. Historically, learning and self-esteem have been inextricably linked and each of them can 
either help or hinder the other. According to the research, students with greater selfesteem are more likely to be successful academically in school (Marsh, 1990). Additionally, higher self-esteem is related to more favorable attitudes toward school, more positive behavior in the classroom and heightened popularity with other students (Cauley \& Tyler, 1989; Metcalfe, 1981; Reynolds, 1994).

Individual differences. Although certain fundamental principles of learning and motivation may be uniformly applicable to all learners, individuals do possess unique skills, abilities and learning preferences. Learning environments that recognize and accommodate varying cultural differences and contexts are generally considered the ideal. Additionally, individuals form a personal basis for the construction of knowledge that embodies both cognitive and social elements. Through the social interaction with others these "separate realities" undergo modification and are expanded to include varied perspectives. Adoption of this multiple perspective viewpoint provides for increased understanding of individual differences, as well as an understanding of the influence of intrinsic beliefs on behavior (APA, 1995, 1997).

\section{Elements of Effective SI Instruction}

The implications of the foregoing learning principles with regard to educational practices are far-reaching. They impact the areas of instruction, curriculum, assessment, instructional management, and instructor education. Conceptually, Supplemental Instruction (SI) incorporates both cognitive and social aspects of constructivism, thereby having at its core, the critical elements of effective instruction. The upcoming sections of this literature review explore effective instruction according to constructivist principles and discuss in detail exactly how the SI program is informed by constructivist ideas. 
Effective instruction according to constructivist principles should accomplish the following (Chen, 2002):

1. Provide opportunities for peer interactions that awaken the learners' natural curiosity and involve them in their own learning.

2. Address the content of curriculum domains and incorporates processes that advance the acquisition and integration of knowledge within them.

3. Offer a system of guidance and stimulation that assists learners in developing better conceptual understanding and more efficient ways of thinking.

4. Incorporate informative and constructive feedback while providing for application and practice of newly acquired skills and knowledge.

5. Provide for acquisition of various learning strategies and subsequent application in varied content domains to assist learner in the development and effective use of the mind.

6. Provide for the development of higher-order thinking and meta-cognitive learning strategies through the use of problem solving, debate, complex decision-making, and group discussion.

7. Promote understanding of individual differences by providing principles of thinking which shed light on the development of attitudes and beliefs.

8. Empower the learner in planning future areas of focus and facilitating application of new knowledge and skills.

9. Promote cooperation and individual mastery in a noncompetitive atmosphere.

10. Provide for improved knowledge construction through discussion and shared understanding among group members. 
A popular definition of the constructivist learning environment describes it as "a place where learners may work together and support each other as they use a variety of tools and information resources in their pursuit of learning goals and problem-solving activities" (Wilson, 1995, p. 27). This is not to say that all constructivists agree on one view of the learning environment. After all, for constructivists the view is dependent upon the focus and the nature of the project. However, the model environment is expected to exhibit the nine characteristics described earlier (Chen, 2002) and embrace the learning principles listed above.

\section{Supplemental Instruction is informed by Constructivist Ideas}

Supplemental Instruction, by coupling the cognitive constructivist principles of Piaget with the social constructivist principles of Vygotsky, easily meets these criteria. Academic discourse concerning the differences between these two theorists place the critical difference in the locus of cognitive development. The contrast between the theories is rooted in Piaget's belief that children construct knowledge through actions on their surrounding environment(s) (or more simply one builds knowledge to understand) and in Vygotsky's claim that knowledge acquisition and the growth of understanding is social in origin (Cole \& Wertsch, 2002).

Considering the differences, it is probably important to point out that the two theories are not mutually exclusive and that both Vygotsky and Piaget acknowledge that the relationship between the individual and the social is "necessarily relational" (Cole \& Wertsch, 2002). Cole and Wertsch also state that much is yet to be learned from both Piaget and Vygotsky and that frequently, when considered together, the strengths of one theorist compensates for the weakness of the other. 
Applying the work of Jean Piaget. The decision to base SI on sound constructivist principles was a conscious one. This developmental perspective shifts the burden of responsibility to the knowledge provider and assumes that students will learn if the proper conditions for learning are in place. These proper conditions, according to constructivist principles, must be centered on the learner and not the subject to be learned. At the time the SI model was created, the leading authority in the developmental field was Jean Piaget (Martin \& Arendale, 1993).

Piaget is best known for formulating a comprehensive model of cognitive development and many of his ideas have been incorporated into the educational theory of constructivism. The conclusion in this line of research as it is applied to SI is as follows: Historically, traditional university instruction has been set on Piaget's formal operations level. Instructors continue to assume that all students are fully formal operational, largely because they have met the academic requirements for entry to the institution (Sutherland, 1999). However, according to Sutherland (1982) and Shayer, Kuchemann, and Wylan (1976), it should not be assumed that all adults can think in formal operational ways. Research by Arons (1976) found that $50 \%$ of first-year higher education students had not developed the formal or abstract operational reasoning skills described by Inhelder and Piaget (1958). In a report to The National Resource Center for the Freshman Year Experience, Martin, Blanc, and DeBuhr, (1983) opined that no significant increases in this proportion have been made since the Arons's study in 1976. For those students who have not attained the formal maturity which Piaget and Inhelder pointedly described, a host of academic problems can result. These problems may not be readily apparent in introductory courses because the exams, often multiple-choice and true/false formats, are 
oriented to detail and the reinforcement of rote memory. Consequently, academic problems may only surface in later, more advanced courses where assessment measures require students to demonstrate critical thinking and integration and application of their knowledge of course content (Chaffee, 1992).

Many students in tertiary educational institutions have not yet developed the abstract reasoning that allows them to learn new ideas by simply reading text and listening to lectures. In the existing SI model, therefore, the theoretical foundation is constructed based on Piagetian levels. In the constructivist context, information and knowledge are viewed as distinctly separate entities. From the Piagetian constructivist perspective, information can be gained simply by the telling. However, Blais (1988) stated that "gaining knowledge means gaining expertise" (p. 4). Put another way, students must be actively involved in constructing knowledge and in understanding how they are to use it. Simply telling students what they need to know or understand can have the effect of reinforcing the remedial processing that has been the tradition on university campuses (Blais, 1988). Martin and colleagues at the University of Missouri-Kansas City contend that Supplemental Instruction promotes the transition from concrete to formal operational levels of thought, which as indicated earlier, is a critical point because many students have been found not to have developed the formal, abstract reasoning necessary to learn and understand new ideas by listening to a lecture or presentation.

One might ask exactly what formal operational thought is and how it differs from concrete operational thought. Simply put, formal operations involve the separation of thought from reality. In the formation of hypotheses, non-real possibilities need to be called upon for inspiration that can be later tested against reality (Sutherland, 1999). Peel 
(1972) put a strong emphasis on the ability to predict outcomes in superficially different situations. To illustrate the differences between concrete and formal operations, Peel developed a concept of imaginative thought, as opposed to the content-dominated thought of the concrete operational thinker (that he labeled describer thought). Peel observed that in all educational courses and subject areas, imaginative judgments are rich and broad in content, as contrasted with the partial and circumstantial observations of the describer stage. To describe the thought of the formal operational thinker he adopted the term explainer thought. This does seem justified as explainer thought primarily answers the question "Why?" as opposed to the "How?" question and description of features associated with concrete thought (Sutherland, 1982, 1999). Those students who are locked into the concrete operational way of thinking will require entirely different teaching methods (Sutherland, 1999), a highly unlikely occurrence in the crowded college and university classrooms of today. Programs that precipitate the transition from concrete to formal operational thought would seem to be the more practical and less costly alternative. SI leaders are expected to model the higher-order thinking and learning strategies associated with formal operational thought, and are trained to elicit responses and engage students in activities that promote functioning on the higher intellectual level required of post-secondary work (Congos, 2002; Ogden, Thompson, Russell, \& Simons, 2003).

Applying the work of Lev Vygotsky. Vygotsky $(1962,1978)$, in his theory of the zone of proximal development (ZPD), described a zone or gap between where learners operate independently and a higher level where they would operate if interacting with more competent peers. More specifically, "the distance between the actual 
developmental level as determined by independent problem solving and the level of potential development as determined through problem solving under adult guidance - or in collaboration with more capable peers" (Vygotsky, 1978, p. 86). He asserted that through continued practice and interaction with more capable peers, learners increase their capability to think, and are consistently encouraged by these more competent peers to extend themselves to higher levels of thought (Vygotsky, 1978). He further observed that collaborative learning activities in peer groups created independent thinkers, which is consistent with the goals most instructors have for their students and a foundational element of Supplemental Instruction.

The SI model stresses these collaborative learning strategies and has relied on them since its inception (Tomlinson, 1989; Whitman, 1988). Supplemental Instruction is identified as collaborative largely because of informally asked questions and open-ended tasks. One responsibility of the SI leader is to guide students as they move upward in operational levels. For example, SI leaders might focus on intellectual tasks such as the identification and control of variables, a reasoning skill that is common to both the natural and social sciences. SI leaders also work to help students attain academic maturity by helping them to analyze their own learning. In simple terms, the most skilled and experienced learners know how to judge their own understanding and how to frame questions that will further it (Martin \& Arendale, 1993). Further, such collaborative group sessions facilitate development of important skills that students can employ throughout their collegiate career. In keeping with this concept, Brown (1994) has explained that collaborative learning engages learners in the construction of shared meaning that advances understanding of the discipline. 
The increased interaction and involvement central to SI, and advocated by Vygotsky (1978), enables students to extend themselves to higher levels of cognition. The process of Supplemental Instruction is designed to assist students in the acquisition of basic learning enhancement skills which, through ongoing application, allows students to raise the level of their reasoning skills and processes. These outcomes are why the SI model stresses collaborative learning strategies and has relied on them since its inception (Tomlinson, 1989; Whitman, 1988). In addition to helping students perform better academically, the use of collaborative learning helps SI provide the ideal environment for students to become better aware of the role of individual differences in learning situations, gain additional perspectives and study techniques and progress further individually by working together in a successful collaborative effort (Martin \& Arendale, 1993).

Supplemental Instruction and Social and Emotional Variables

The various disadvantages that affect community college students demonstrate congruence with factors long associated with lack of college success. Vincent Tinto (1993) has identified four experience factors that are likely to impact the unsuccessful student. These are (a) difficulty adjusting to the college environment, (b) experiencing academic and social difficulties, (c) a divergence between student expectations and institutional demands, and (d) the feeling of being socially isolated.

Adjustment. Tinto (1993) recognized that the adjustment to the tertiary academic environment presents a problem to all new students. A contributing factor may be the inability to separate from prior associations. To some administrative authorities, this 
problem is insurmountable. The results can be observed in the attrition statistics. In a

1990 interview with Spann, Tinto stated:

We must make sure that classrooms do not disenfranchise or isolate students by their structure or by their content. We have to be concerned about the classroom experience as a liberating, integrative experience for all, not just some, students. We also have to think about the ways in which the classroom experience can lead students to develop supportive, rather than competitive, peer relationships. That is, we must seek ways to integrate, not isolate, the academic and social experiences of students.

To have one without the other is a mistake. (Spann, 1990, p. 22)

Consequently, as Tinto advised, the ideal learning experience should achieve the integration of both academic and social elements. Such integration encourages the development of supportive peer relationships, which not only reduce the anxiety connected with, but also go a long way toward filling the void created by the loss of prior associations. Forging these valuable peer relationships does much to reduce the feelings of isolation; those feelings of being an outsider and not being part of, or connected to, the academic community. Tinto also later observed that Supplemental Instruction, a program that fosters such peer relationships, had a positive impact on several student outcomes (Tinto, 1997).

While SI has little direct effect on the reduction of separation anxiety, it is designed to provide some guidance and friendly discourse through the informal study groups and the gentle assistance of the SI leaders. According to Martin, Blanc, and Arendale, (1996) a large number of students fail to achieve their academic goals because they have no experience in the college or university environment. The role of the SI leader, usually a peer, is critical to the effectiveness of SI. SI leaders can help these students comprehend course expectations, model ways of how successful students 
process information, assist students in developing strategies to organize information, and help students learn to make the most of class and university resources.

Isolation. Institutions of higher learning have ongoing issues with the constantly evolving student population and must take proactive steps to provide an air of community among the students. Collaborative learning activities, smaller class sizes, more student and professor interactions are some suggestions for developing a welcoming environment (Tobias, 1992). These are characteristics of Supplemental Instruction.

Supporting the assertions of Supplemental Instruction, Richard Light's (1990) research reported that students "who form study groups report that they both enjoy their work more, and feel they learn more, because of the academic discussions within these groups" (p. 18). Moreover, "In every comparison of how much students learn when they work in small groups or when they work alone, small groups show the best outcomes" (Light, 1990, p. 10). According to Sandberg (1988), these types of experiences improve learning and feeling in the student's cognitive and affective domains. More simply, the student makes progress in the sophistication and refinement of thought (this is often the transition from concrete to formal operational thought), and with the learning connected affective factors, such as internal expectations, feelings, and beliefs that can either support or undermine learning.

The quantity, quality and retention of learned information is directly impacted by beliefs regarding self-efficacy, relevance of personal goals and values, individual expectations, state of mind and related intrinsic motivations. Astin (1987) noted that collaborative learning is a significant and vital method for teaching students how to work together in groups. "The student's peer group is the single most potent source of 
influence on growth and development during the undergraduate years" (Astin, 1983, p. 398).

Research has also supported Supplemental Instruction by indicating that studentto-student and student-to-faculty interactions are vital to the success of students (Cohen, 1981; Feldman, 1976; Marsh, 1984; McKeachie, Pintrich, Lin, \& Smith, 1986). For example, Tinto (1998) found that learning increased dramatically for students when classes were structured around peer learning that took place outside the classroom. In addition to establishing ties between peer relationships and academic outcomes, researchers have also demonstrated that within the context of collaborative learning activities, peer interactions can facilitate involvement as well as the development of intellectual skills (e.g., Gauvain \& Rogoff, 1989; Radziszewska \& Rogoff, 1991). Another item of interest is that specific academic enablers have been connected with peer collaborative learning. Included are intellectual enablers such as positive involvement in learning activities (Azmitia, 1988; King, 1990; Radziszewska \& Rogoff, 1991), improved problem-solving ability (Radziszewska \& Rogoff, 1991; Tudge, Winterhoff, \& Hogan., 1996), and improvements in recall and comprehension of material (Azmitia, 1988; King, 1990), as well as positive social communication and negotiation skills (Fuchs, Fuchs, Bentz, Phillips, \& Hamlett, 1994; King, 1990).

Similarly, decades of documentation have emphasized the importance and influence of informal student-faculty interaction on the patterns of student learning and growth (Lamport, 1993; Pascarella \& Terenzini, 1976, 1978; Theophilides \& Terenzini, 1981). As a primary agent of college culture, such interaction has been shown to exert a powerful influence on the attitudes, interests, and values of college students (Chickering, 
1969; Newman \& Newman, 1978; Pascarella, 1980; Pascarella \& Terenzini, 1978;

Terenzini \& Pascarella, 1980). Additional studies have provided evidence that informal student-faculty interaction has an important role in the learning environment (Churukian, 1982; Cooper, Stewart, \& Gudykunst, 1982; Davis \& Young, 1982; Feldman, 1983; Rogers, 1962; Theophilides \& Terenzini, 1981).

Chickering and Gamson (1987) indicated that instructors who encourage student interaction in and outside of the classroom could improve motivation, attitude, and personal and social development. They noted that "working with others often increases involvement in learning" (p. 3). Learning together in groups, promotes the active and collaborative learning that helps students succeed (Bouton \& Garth, 1983). This studentstudent interaction outside the classroom is important because as a rule, large class size inhibits interaction and offers little opportunity for students to engage in meaningful discourse with fellow peers (Arendale, 1994). Supplemental Instruction sessions are designed to provide opportunities for students with varying abilities to assist one another, actively encouraging meaningful interaction.

Academic difficulty. Tinto (1993) identified academic difficulty as a key factor in student attrition. The inability to meet minimum standards is often the stimulus to voluntary withdrawal or involuntary dismissal. This was the chief issue that SI was designed to address. The underlying assumption was that improving student academic performance would counter attrition, whether voluntary or enforced. This assumption is supported by a body of research that shows a correlation between poor (actual or perceived) academic performance and student attrition (Cash \& Bissel, 1985; Cesa, 1980; Edwards \& Waters, 1982; Jacobs, Brigman, \& Friedman, 1982; Johnson \& Buck, 1995; 
Keller, 1979; Rodney, 1981; Sandler, 2000). Since the final course grade is indicative of the level of academic performance, and poor academic performance has been shown to be correlated with student attrition, higher final course grades, like those reported achieved by SI participants, consequently decrease student attrition rates (Arendale, 1998). Several studies have shown that SI is strongly related to higher final course grade (see Congos, 2002; Martin \& Arendale, 1993), and also has a positive impact on student persistence (Center for Supplemental Instruction, 2000; Congos, 2002).

Incongruence. For the supporters of SI, possibly the most problematic of these four factors to address is the issue of incongruence. Tinto (1993) defined this as the mismatch between the individual student's needs, interests and preferences and those of the institution. The source of incongruence is in the individual perceptions of not meshing well, of being out of sync if you will, with the social and intellectual realities of institutional life. The proponents of SI suggest that by providing students with peer (or near-peer) interaction that extends beyond the limited contact with faculty and staff, SI instills a broader and more favorable view of the institution. Likewise, meeting and tasking with various groups of peers in collaborative learning situations is said to significantly expand and enhance the student's contact with the institution. And finally, the academically successful student will always negotiate her or his way through the institution with far more confidence than the marginal student (Martin et al., 1996).

As Chickering and Gamson (1987) pointed out in their Seven Principles for Good Practice in Undergraduate Education, good practices encourage, among other things, cooperation among students and the promotion of active learning. These "good practices" for all intents and purposes mirror the major goals of the constructivist 
principles mentioned earlier. For example, under the guidance of an SI leader, students interact with peers in a collaborative environment to master course content, as well as to master the skills necessary to learn that content. SI leaders are instructed to create a noncompetitive environment where students feel free enough to attempt to find solutions and tap in to the knowledge of peers to evaluate and compare those attempts. SI leaders are likewise told to model effective higher-order thinking and learning strategies as well as to actively motivate students to acquire the range of skills that will help them perform and succeed as independent learners. As Congos (2002, p. 77) has noted, in theory, "SI leaders teach what students have to learn to learn what the faculty has to teach."

SI leaders do not repeat lectures or frame content questions, but rather are trained to awaken curiosity and elicit such thoughtful responses from session attendees as to encourage discussion of the information provided through the lecture and in the textbook. SI leaders may also encourage the use of analogies to promote understanding, and to aid in future recall. SI sessions help students acquire and refine skills that carry forward to other courses, and encourage socialization and faculty contact by recommending membership in clubs that have faculty participation (Congos, 2002).

Student participants in SI pool their content knowledge and are encouraged to engage in continuous self-assessment. They also receive constant feedback with regard to their level of understanding of the subject matter. SI leaders will often utilize sample tests but will have the SI attendees perform the thinking, analyzing, and formulation of possible exam questions. SI leaders are to encourage sharing of information on personal study skills - those that were effective and those that were not - with additional discussion as to the reasons why. SI leaders are to help students to realize the 
commitment of time necessary to succeed in college, by acting as a resource for learning success techniques. SI sessions communicate high expectations, and help students to rise to meet them. Students in SI are allowed to freely participate according to their particular assets. Prior knowledge base, special techniques, talent for explaining to others, all are to be shared and valued, and these diverse talents may well come to be wholly appreciated by all (Congos, 2002).

The Role of Collaborative Learning in Supplemental Instruction

Although some tend to emphasize the role of collaborative learning over cooperative learning in SI, or quite simply do not distinguish between the two, Supplemental Instruction is a model based on a combination of both collaborative and cooperative learning techniques (Johnson, Johnson, \& Smith, 1991; Tomlinson, 1989; Whitman, 1988). What makes it unique among traditional academic support programs, and accounts for the success in its three goal areas (i. e., grade improvement, attrition reduction, and student persistence) is its particular emphasis on collaborative learning techniques.

Collaborative Learning is a model of teaching that possesses certain common features and attributes and also exhibits several variations. The core features include the following: (a) "learners work in teams to gain mastery of academic concepts and materials, (b) teams are comprised of members at varying levels of achievement, (c) teams are mixed in terms of race and gender, and (d) systems of reward have a group rather than individual focus" (Arends, 1994, p. 344).

Not surprisingly, given the malleable nature of the collaborative learning model, there are varied interpretations in the literature as to what constitutes collaborative 
learning. Also not surprisingly, the majority of these descriptions share common characteristics. Following are sample interpretations that represent the majority of those found in the literature. "Collaborative learning's intention is to focus on the creation of personal meaning and internally persuasive understandings through dialogue and discussion" (Davidson, 1994, p. 23). Smith and MacGregor (1992, p. 11) have remarked, "Collaborative learning is an umbrella term for a variety of educational approaches involving joint intellectual efforts by students, or by students and teachers together."

As indicated by the preceding statements, no consensus of opinion has been reached on what precisely constitutes collaborative learning. Some view it as a separate method of teaching and learning that borrows from the cooperative method but differs in significant ways, while others see it as a general category that includes a number of forms of cooperative teaching techniques. Cooperative learning has been defined by Murray (1994) as a "family of instructional practices in which the teacher gives various directions to groups of pupils about how to work together..." (p. 6). Although many interpretations may appear on the surface to describe the usual classroom environment (e.g., Smith \& MacGregor, 1992), the important distinction is the active involvement of students at highly diverse achievement levels who are not in direct competition.

To wit, in a personal communication to Gamson, William Whipple offered the opinion that the structure of cooperative learning is essentially "noncompetitive" learning, in which students who work together toward accomplishing a common goal are rewarded for their efforts (Gamson, 1994). Collaborative learning goes one step beyond cooperative learning by involving students in a positive confrontation over power and authority. Cooperative learning techniques support and maintain the traditional power 
and authority structures, whereas collaborative learning techniques challenge them. Educators have come to realize that students' success in the twenty first century will rely on their ability to become lifelong learners. An argument has been made that in order to foster the development of the specialized skills required of the lifelong learner, a departure from direct instruction and the adoption of a different approach to teaching and learning is required (Conway, 1997). Cooperative learning still employs the teacher or traditional instructor as the one giving direction whereas the collaborative approach puts that direction and the recognition of roles and responsibilities into the hands of the students. It is this transfer of power and authority to the student/learner that helps them develop the skills deemed so necessary to future success - the skills of the lifelong learner.

Assorted other models of engaged group learning present collaboration as a method to assist students in constructing knowledge as well as introduce students to the specific vocabulary and values of the discipline. As is generally known, school subjects have unique vocabularies, definitions, bodies of knowledge, and proven methods for attaining and gathering knowledge and evidence that all new students of the subject must acquire in order to learn (Blumenfeld, Marx, Soloway, \& Krajcik, 1996). Brown (1994) defined collaborative learning as a task that involves students in the construction of shared meaning, which subsequently advances their learning and understanding of the discipline. Moreover, according to Webb and Palincsar (1996), collaborative learning expands upon cooperation in a number of ways. They contend that collaboration lays an important foundation for communal knowledge through active discourse. Students engaged in discussions among themselves first learn to recognize and then draw upon 
each other's expertise. In this way, they learn from each other (Bruer, 1995). Because of this critical factor, collaborative models in general, are not highly or rigidly structured. The tasks are typically more open-ended and questions are asked informally, without the usual agenda-related constraints. Supplemental Instruction is said to achieve the optimal balance between both cooperative and collaborative learning modalities. The cooperative element is represented through structured group learning and the collaborative element is expressed through the open-ended tasks and informal questions.

The chief difference between Supplemental Instruction and other collaborative learning models is the presence of a Supplemental Instruction leader. This SI leader acts as a facilitator who keeps the group focused on the content material and also functions as a model student by attending class, taking notes, and asking appropriate questions. Hence, the SI leader functions as a peer facilitator who works closely with the students instead of having the group operate independently without the benefit of guidance or facilitation (Dimon, 1988; Johnson et al., 1991). Research findings have consistently demonstrated the efficacy of peer facilitation in aiding academic achievement (Goldschmid \& Goldschmid, 1976; McKeachie et al., 1986; Whitman, 1988).

\section{Empirical Findings on the Use of SI in Higher Education}

In developing the present study, the researcher conducted an extensive review of the literature on Supplemental Instruction identifying specific studies as particularly relevant because of either their research design or their content elements. The individual studies described below are quantitative studies that targeted science or quantitative courses. 
Burmeister (1994) suggested that SI attendance is highly correlated with higher final course grades in college algebra, calculus, and statistics. That ambitious study included data from 45 institutions with a total of 11,252 students who were enrolled in 177 classes.

Kenney (1989) utilized a nonequivalent control group model to examine two large business calculus lecture sections taught by the same instructor; one with a teacher assistant (TA) conducting two discussion sessions per week $(n=51)$ and the other with an SI leader conducting two SI sessions per week $(n=50)$. Her findings indicated a significantly higher course-grade mean for the students who participated in Supplemental Instruction, operating in conjunction with factors such as mathematical aptitude, prior academic success, and attendance rates. In a multiple regression analysis, the final course grade was the dependent variable and the SAT-Verbal, SAT-Math, Mathematics Level I test score, high school ranking, discussion session attendance, and group membership (SI or non-SI) were the independent variables. These variables accounted for $36.8 \%$ of the variance in this model. Further $t$-tests showed that three of the variables contributed significantly to this variance; group membership $(b=0.5055, d f=81, t=2.26, p<.05)$, high school ranking $(b=0.0210, d f=81, t=3.12, p<.001)$, and session attendance $(b=$ $0.0174, d f=81, t=2.05, p<0.05)$.

Due to the significance of the regression coefficient, Kenney (1989) concluded that students who had experienced SI performed at a higher level of achievement. Unfortunately, the author did not provide information on how much of the variance was accounted for by SI attendance alone. Still, by dividing the lectures into three equivalent 
discussion sessions (one group received assistance in the Supplemental Instruction model; the second group received assistance in the traditional tutorial - content-based discussion-only, with the assistance of a graduate teaching assistant; and the third group in each class did not participate in the study), Kenney did adequately address any effects that double exposure to course content might have had on student performance.

Lundeberg (1990) used both quantitative and qualitative techniques to evaluate SI in Chemistry courses. The findings, based on a 2-year study with 148 students, indicated that SI contributed to higher mean final grades and lower rates of D, F, and course withdrawals for SI participants. The qualitative component of the study made use of field notes, open ended questionnaires, and SI leader journals to gather data. As a result, six factors related to how SI might be helpful were revealed. These were (a) accommodating needs of diverse learners, (b) understanding versus memorizing, (c) depth versus breadth of discussion, (d) relationships between ability, knowledge, and confidence, (e) social relationships with students, and (f) challenges to SI leaders' knowledge.

The National Center for Supplemental Instruction (1997) published a review of the many, quasi-experimental research studies conducted to assess the effectiveness of SI. The basic design of the various studies compares performance of a voluntary treatment group (SI participants) with a control group of non-SI participants. In one study, conducted at the University of Missouri-Kansas City (UMKC) in 1996, the data suggests a relationship between higher final course grades and an increase in frequency of SI attendance. The study compared the final course grades of 854 non-SI participants with 736 SI participants who attended one or more SI sessions. The mean final course grade of the non-SI group was 2.37 as compared with 2.79 in the SI group. And, of those in the SI 
group who attended 8 to 11 SI sessions, the mean final course grade was 2.88 . Using the chi-squared test, the level of significance for the difference when comparing the baseline non-SI participant group and the individual SI participant group was 0.05 (Center for Supplemental Instruction, 1997).

\section{SI and Related Effects on Student Participants}

Researchers have also studied various factors associated with the academic achievement noted above. Some have focused on specific effects of participation in SI programs on student persistence and attendance, others on participants' perceptions of the program or interactions among participants, and yet others on at-risk students.

Persistence. Further data from an examination of college graduation rates at UMKC in the years 1989 to 1996 suggest that SI has a positive impact on persistence. The graduation rate of SI participants was $46.0 \%$ as compared to the $30.3 \%$ of non-SI participants. This difference was significant at the .01 level. Level of significance of difference: 0.01 using the chi-squared test. Additionally, in an analysis of national SI field data of the years 1982 through 1996, involving 270 institutions, 4,945 courses (across 30 academic departments), and 505,738 students, SI participants at all institutions were shown to earn higher final course grades ( 2.42 vs. 2.09 ), earn a higher percentage of A and B final grades (46.8\% vs. $35.9 \%$ ), and represent a lower percentage of D, F, and W final grades (23.1\% vs. $37.1 \%)$. Level of significance of difference: 0.01 using independent samples $t$-test for final course grade category, and 0.01 using chi-squared test for the percentage of letter grade categories. Finally, data analyses were employed to determine the utility and effectiveness of SI for students from various ethnic backgrounds. These analyses, involving 13 institutions (three 2-year public, four 4-year 
private, and six 4-year public institutions) and 2,410 SI participants, revealed that with all students of color, mean final course grades were 2.02 for SI participants and 1.55 for nonSI participants. The researchers found a significant difference between the group using SI and the non-SI group at the $p=.01$ level using an independent samples $t$-test (Center for Supplemental Instruction, 1997). This indicates that SI was an effective strategy for increasing the level of student persistence.

Social interaction. Lundeberg and Moch (1995) were interested in the process of social interaction among women learning science. Gathering their data from college chemistry classes, they made use of SI session observations, SI leader journals, focus group interviews, and surveys. Related data were combined into clusters to identify factors related to the social interaction elements of SI. Two major factors were discovered, culture and cognition. They identified four qualities as characterizing the culture of the SI session. These were (a) spirit of cooperation; (b) spirit of community, (c) a shift of power from the SI leader to the students, and (d) risk taking behavior on the part of SI leaders and students. In addition, they found three dominant patterns that emerged from the data and related to the SI influences on cognition. These were (a) SI sessions confirmed the capacity for learning science, (b) SI sessions were designed to meet individual students' needs, and (c) SI sessions related concepts to other concepts and that ideas were connected with experiences.

Participants' perceptions. Lockie and Van Lanen (1991) also examined the impact of SI in college chemistry courses. However, their study's main purpose was to examine how the SI participants perceived the SI program. Lockie and Van Lanen's findings uncovered a critical factor: Consistent and frequent student participation in SI 
sessions is essential for SI to have a measurable effect on performance. In addition, their findings demonstrated that collaboration between the SI leader and students is vitally important to the success of SI.

Attendance. Van Lanen and Lockie (1997) conducted further research on the effects of SI in chemistry courses. In this study however, they identified SI participants as those students who had attended six or more sessions. Prior studies had used one to three sessions as the definition of SI participation. Here also the researchers discovered that SI participants received a higher mean course grade. They suggested that because of the complexity of skills required to understand chemistry, higher levels of attendance are necessary to show consistently positive results. Their examination of SI participant reports revealed three major reasons why the participants felt SI was helpful. Participants reported that (a) the chance to work problems out an the board and to see others working problems out on the board, (b) the opportunity to share information, and (c) the chance to help each other made SI activities helpful to them in their studies of chemistry.

At-risk students. In a longitudinal study designed to ascertain the short and long term effects of SI on at-risk students at a large urban university, Ramirez (1997) demonstrated that SI participants benefited in both the short and long term. Academically-under-prepared or special admit students $(n=337)$ improved their course grade by $0.70 S D$ more than non-SI peers $(n=379)$. Mean end of semester course grades were 2.52 for SI participants and 1.82 for non-SI students. Semester GPAs were 2.55 and 2.10 respectively. This difference was significant at the .01 level of significance. In addition, Ramirez demonstrated that among these at-risk students, SI had a substantial impact on student persistence. 
In a similar vein, Ogden and colleagues (2003) demonstrated that the conditional (at-risk) student, when receiving SI, is "brought up" to the level of the non-SI traditional student. Independent $t$-tests indicated that conditional students receiving SI were not significantly different from traditional non-SI students for either target course grade $(t=$ $1.4, d f=$ not reported,$p=.16)$, semester GPA $(t=.43, d f=$ not reported, $p=.76)$, or cumulative GPA $(t=.12, d f=$ not reported, $p=.91)$, suggesting that participation in SI imparts the various learning strategies necessary to succeed in college. It should be mentioned however, that the beneficial effects of SI were observed to weaken over time, as suggested by the decline of the conditional students' GPAs. The authors suggested that refresher SI sessions appeared to be required.

Researchers McCarthy, Smuts, and Cosser (1997), critical of the methods of the analysis employed in the preceding studies, and insistent that the effect of SI on academic achievement had not been truly isolated, employed a more sophisticated multiple regression. The final course mark in the SI-supported course was treated as the dependent variable, and written as a linear function of the quantified independent variables known to affect student performance. Coefficients for each variable, as well as the reliability estimate for each coefficient indicated how strongly any given independent variable impacted final performance. They opined that the results of the multiple regression employing only three variables (SI sessions attended, academic ability in the university clime (measured by the aggregate of all common courses taken and excluding the SI supported course) and preparedness level would provide a much clearer picture of SI's actual influence. 
Employing an admissions rating system which assigned points for letter grades according to a prescribed formula, they compared the mean admission ratings (which equate to level of preparedness), and also did a comparison using a chi-squared goodness of fit analysis, and found no significant difference between SI and non-SI groups. However, the mean mark in the target course for students in the SI group was $6.4 \%$ higher than that obtained by the non-SI group. In addition, among "disadvantaged" students, the performance of SI students was statistically significantly better $(p<0.05)$. In their summary of findings, the authors concluded that (a) the results of the SI intervention were not unlike those of other "successful" interventions, (b) that SI tends to greatly benefit the underprepared or at-risk student, and (c) that analyses which were not statistically significant did tend in the direction of supporting the positive effect of SI (McCarthy et al., 1997). These conclusions are remarkably similar to those arrived at in the earlier studies.

It is therefore safe to conclude that the body of research on SI demonstrates the program's success across a range of settings and applications. This is consistent with the notion that the collaborative learning strategies that form the basis for constructivism, the theoretical underpinning of SI, should result in efficacious learning activities. SI advocates connect the program's activities to changes in student study behaviors leading to their improved academic performance; however, this connection has not been empirically confirmed.

\section{Study Behaviors and Achievement}

The knowledge and application of effective study behaviors has long been associated with overall academic competence (Agnew et al., 1993; Elliott et al., 1990; 
Jones et al., 1993; Jones et al., 1995; Jones et al., 1996; Lammers et al., 2001), consistently demonstrating positive outcomes across varied content areas and among diverse learners (Gettinger \& Seibert, 2002). Despite the fact that some students independently develop effective study behaviors, research has shown that even students achieving at standard levels may move through their school years without ever having developed effective study behaviors (Chaffe, 1992; Nicaise \& Gettinger, 1995).

In their studies with undergraduate students, Jones, Slate, and Kyle (1992), and Lammers et al. (2001) specifically demonstrated the relationship between effective study behaviors and academic achievement, revealing that a major weakness in study behaviors is poor time management. As a rule, college-level students tend to procrastinate, leaving the lion's share of subject material review until the evening right before the exam (Bailey \& Onwuegbuzie, 2002). Research has also indicated that between one-half (Agnew et al., 1993) and two-thirds (Slate et al., 1998) of undergraduate level students utilize suitable study behaviors.

Viewed as academic enablers, effective study skills and behaviors function as critical learning tools. Effective studying incorporates a number of coordinated cognitive skills and processes that enhance the efficiency of student learning (Gettinger \& Seibert, 2002), along with the application of necessary activities and behaviors (Young, 2002). Effective study behaviors have been found to include successful time management and possession of a healthy attitude toward learning (Jones et al., 1992).

Study behaviors are not the same as study skills, although they are no doubt related (Bailey \& Onwuegbuzie, 2002). The developers of the Study Behavior Inventory (SBI) provided a simple and illuminating differentiation. Study skills, they tell us, are the 
potentials for action, while the actions themselves are the study behaviors (Bliss \& Mueller, 1987). Studying, the application of study skills is skillful. It requires practice with certain techniques that assist the learner in acquiring, organizing, retaining, and using information. Studying is intentional, requiring not only the knowledge of study skills, but the conscious effort to apply them. It is also highly individualized. Even when learning is acquired through social communication, individual study behaviors still have a critical role in academic achievement (Kucan \& Beck, 1997). This suggests that a successful student assistance program needs to ensure that effective study skills and behaviors persist outside of the group sessions.

With regard to the features of student study behaviors and the contributory elements, the authors of the SBI have identified three distinct factor groupings. The first concerns the student's expressed feelings of low self-esteem and lack of competence. The second concerns behaviors associated with preparation for ongoing and routine (shortrange) academic tasks (e.g., reviewing notes, completing assigned readings). The third deals with behaviors involved in the planning and execution of long-range academic tasks (e.g., writing term papers, studying for exams). These researchers indicated that sufficiency in all three groupings is strongly related to academic success (Bliss \& Mueller, 1987).

SI's Impact on Study Behaviors - Theoretical Considerations

SI leaders act as both model students in the class and facilitators of the SI sessions. Students observe the SI leaders arriving on time to class, taking notes and asking questions during class. The SI leaders are trained in proactive learning and study strategies. Following each class, during the SI session, the SI leader integrates the 
subject matter content with good study behaviors, facilitating students' digesting and processing course content. Students are to engage in collaborative efforts designed to help them develop the behaviors that will allow them to become better students.

Since, as was mentioned earlier, (and also identified as critical by the authors of the SBI), the quantity, quality, and retention of learned information is directly impacted by beliefs regarding self-efficacy, individual expectations, state of mind, and other related intrinsic motivations, students empowered by participation in SI should experience an increase in self-esteem and feelings of self-efficacy as well as in achievement. The student's natural curiosity is preserved through the SI techniques of peer interaction, interpersonal support and the imparting of successful strategies to achieve self-discipline, and decrease or eradicate the effects of low self-esteem (Arendale, 1994).

Students in SI are said to attain academic maturity by receiving the leader's assistance in analyzing their own learning. Expert learners know how to evaluate their own understanding and how to pose questions that will expand it (Martin \& Arendale, 1993). The SI leader also discusses techniques necessary for successful navigation of the course, and offers advice and encouragement on note-taking, test-taking, and various study strategies. Students may be given oral or written quizzes, or even practice exams (Boylan, 1999). These SI activities specifically address the SBI factors having to do with the preparation for both the short-range (routine) and long-range (upcoming event) academic tasks (Bliss \& Mueller, 1987, 1993). As a result, SI participants should evidence better study behaviors than non-SI students in both these critical areas.

It is important to stress once again that a central responsibility of the SI leader is to integrate effective study skills and behaviors with the course content, and this is a key 
difference between SI and other forms of collaborative learning. SI moves beyond collaborative learning through the planned integration and practice of effective study skills and behaviors (Arendale, 1994). Considering the positive relationship between study behaviors and academic achievement, it may well be that SI's impact on study behaviors accounts for much of the program's reported success. Demonstrating the presence of improved study behaviors in conjunction with higher overall content mastery in students who have participated in SI versus students who have not participated will go a long way in illuminating a likely source of SI's reported effectiveness. SI's Impact on Study Behaviors - Empirical Evidence

Maxwell (1998), in a study involving 19 different instructors, many course sections, and hundreds of students, reported finding evidence that once a community college institutes an SI program to enable students to interact with each other in their studying and coursework, there is an improvement in overall study behavior. SI was moderately correlated with two measures of the frequency of students studying together. Participation in SI was correlated with studying with other students $(r=.27)$, and also with meeting outside class with a group of students to study for a particular course ( $r=$ .24). However, it should be noted that these correlations accounted for only $7 \%$ and $5 \%$ respectively of the variance in the two measures of studying together.

Maxwell cited Cohen (1990) as determining that the size of the relationships is routinely considered to be of medium level magnitude. Cohen (1990) stated that a number of relationships pursued in the behavioral sciences are of small magnitude, which he defines as $r=.10$. This is comparable to the definition of a small standardized effect size for a mean difference $(d=.2)$, suggesting point biserial $r=.10$ for populations of 
equal size. The behavioral scientist typically encounters a great deal of "noise" (measurement unreliability, lack of fidelity to the construct) as he or she moves from theoretical constructs (which include hypothetically strong relationships), to operational realization in measurement. This subsequently weakens the correlation in the population between the constructs as measured. Hence, if two constructs in theory (thus perfectly measured) are expected to correlate .25 , and the actual measurement of each construct is correlated .63 with its associated pure construct, the observed correlation between the two "fallible" measures is decreased to $.25(.63)(.63)=.10$.

Cohen (1990) further stated that given that the above values are not unrealistic, it is likely that frequently researchers seek to reject null hypothesis about $r$ when $r$ is equal to a certain value near .10 . Cohen went on to say that many of the correlation coefficients in behavioral science are of the medium magnitude, this being $r=.30, r^{2}=$ .09. Hence, a medium effect in linear regression suggests that $9 \%$ of the variance of the dependent variable can be attributed to the independent variable. He stated that this degree of relationship is "perceptible to the naked eye of a reasonably sensitive observer" (p. 80). If one examines the area of psychological tests for example, $40 \%$ of the correlation coefficients in the nine clinical scales of the widely used Minnesota Multiphasic Personality Inventory (MMPI), were reported in the literature as ranging from .25 to .35 (Butcher, Graham, Williams, \& Ben-Porath, 1990), suggesting justification for identifying a medium effect size as "a value at the midpoint of the range of correlations between 'discriminably' different psychological variables" (Cohen, 1990, p. 80). 
Also in Maxwell's study, a minimum of $20 \%$ more SI students were studying together outside of the classroom than were non-SI students. As Maxwell pointed out, the limited literature indicates that this moderate magnitude is equal to, or exceeds that of effects achieved by other learning communities. This high level of student collaboration may demonstrate a study behavior learned through the SI program.

While a strong case for the efficacy of SI has been established in the literature, and effective study behaviors have been shown to be strongly correlated with better course grades, it has yet to be demonstrated whether Supplemental Instruction substantially improves study behaviors as claimed. In addition, no one has identified which students' study behaviors benefit the most from participating in Supplemental Instruction. Given that students with strong study skills and effective study behaviors regularly earn the best course grades, such students should consistently demonstrate these exemplary behaviors, whether or not they participate in an SI program. Conversely, those students with deficient study behaviors should demonstrate a marked improvement in both study behaviors and course grade after participation in SI, and non-SI students with deficient study behaviors should not demonstrate this improvement.

The theoretical framework of this study can be represented as shown in Figure 1.

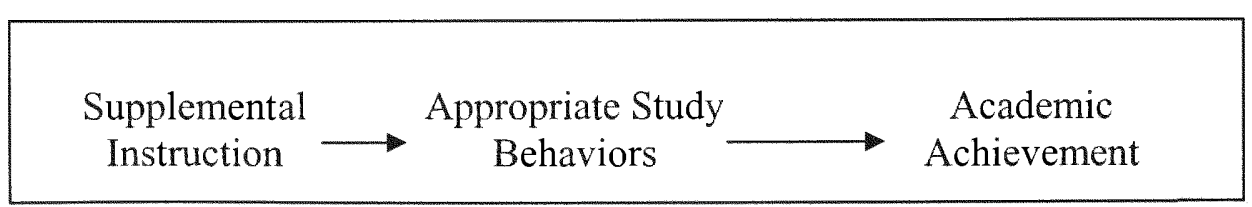

Figure 1. Theoretical path of the effect of supplemental.

The framework suggests that programs of Supplemental Instruction use modeling by the SI leader to facilitate the learning of effective study behaviors by students. Then, 
by integrating these study behaviors with content in collaborative learning activities, these behaviors are reinforced and students learn the course content more effectively than they did prior to entering the SI program. Effective study behaviors are the mediator between the instruction in course content and the learning of this content that manifests itself as academic achievement.

\section{Research Question}

While, as has been noted earlier, there is much empirical evidence that Supplemental Instruction has a positive effect on academic achievement and that there is a strong positive relationship between the use of appropriate study behaviors and academic achievement, the efficacy of Supplemental Education in increasing the frequency of students' use of appropriate study behaviors has not been empirically supported. This research tested this model by investigating the following question: Will students participating in a program of Supplemental Instruction in an Anatomy and Physiology I course have more effective study behaviors and higher course grades than students in the same course who do not participate in a program of Supplemental Instruction?

\section{Hypotheses}

1. After a semester of participation in sections of a community college Anatomy and Physiology I course incorporating Supplemental Instruction students will have higher final examination grades than students in sections of the same course that do not incorporate Supplemental Instruction.

2. After a semester of participation in sections of a community college Anatomy and Physiology I course incorporating Supplemental Instruction students will 
have higher scores on each of the three factors of the Study Behavior Inventory

(Bliss \& Mueller, 1990) than students in sections of the same course that do not incorporate Supplemental Instruction.

\section{Summary}

In Chapter 2, the author examined the relevant literature with respect to the efficacy and application of the SI program, its impact on study behaviors, and the importance of study skills and behaviors to academic success. The history of the Supplemental Instruction program was traced, accompanied by a detailed description of the program, delineating the roles of the SI leader, SI supervisor, and SI faculty member.

The theoretical foundations of Supplemental Instruction were discussed, specifically the underlying principles of constructivism and learner centered approaches to education. Metacognitive principles, affective factors, personal and social factors and individual differences were explored in these contexts. The various elements of effective SI instruction were described in detail.

How Supplemental Instruction is informed by constructivist ideas was thoroughly examined. The combination of Piaget's focus on internal cognitive processes and Vygotsky's focus on sociocultural elements in cognition and knowledge construction was shown to be the foundation for the SI program. Also discussed was the significant role of collaborative learning in Supplemental Instruction.

In addition, the use of the Supplemental Instruction program in higher education was examined in detail. The relationship between study behaviors and achievement was described and the importance of effective study behaviors clearly established.

Theoretical considerations pertaining to SI's impact on study behaviors were examined, 
and SI's impact in this area was subsequently demonstrated by the presentation of empirical evidence. 


\section{CHAPTER III}

\section{METHODS}

A description of the sample, procedure, instrumentation, and data analysis strategies used in this study are provided in his chapter. The research design used in this study was a non-equivalent design using an analysis of covariance as a statistical tool to test for differences in academic achievement and the use of appropriate study behaviors between groups of anatomy and physiology students receiving Supplemental Instruction and those receiving an alternative educational treatment.

\section{General Research Methodology}

This researcher has conducted a quantitative research study, employing a pre-testpost-test, non-equivalent groups, quasi-experimental design. The sample of participants was a convenience sample from the site of the research, with every attempt made to achieve adequate sample size and representative diversity. The data analysis technique was the ANCOVA, reliability-corrected, and therefore made appropriate for use with the non-equivalent groups design (NEGD). Two instruments were used for data collection, one to measure content mastery and the other to measure study behaviors; both administered on a pre-test and post-test basis.

\section{Research Design}

This researcher employed a non-equivalent groups design (NEGD), which some believe is the most frequently employed design in social research (Trochim, 2002). The NEGD's structure is much like the pretest-posttest randomized experiment, minus the defining feature of random assignment (Jackard \& Becker, 1997). In using the NEGD, the experimenter frequently designates as the treatment and control groups; existing 
groups that are assumed to be similar. For example, in educational studies a researcher often selects two comparable classes or classrooms (Trochim, 2002). A researcher strives to select groups that have as many similarities as possible so that comparisons between treatment and control group can be made. Of course, the groups cannot be as comparable as those achieved through entirely random assignment (Jackard \& Becker, 1997).

The researcher of the present study chose a quasi-experimental design due to the virtual impossibility of achieving random assignment to groups. However, the possibility of self-selection bias was controlled for by making the Supplemental Instruction sessions mandatory for all students in two sections of the Anatomy and Physiology I Lecture course. SI sessions led by the same SI leader were scheduled for two separate sections of an Anatomy and Physiology I Lecture course, taught by the same instructor. The non-SI participants in two sections of the Anatomy and Physiology I Lecture course, who participated in a mandatory alternative activity, constituted the control group.

\section{Data Collection}

The technique of data collection entailed administration of both the Anatomy and Physiology I Lecture final exam and the SBI, on a pre-course and post-course basis, to SI and non-SI student-participants, in a total of four sections of an Anatomy and Physiology I Lecture course taught by one instructor. In order to ensure that the participants committed their full attention and resources to the pre-course tests, incentives were provided. For the Anatomy and Physiology I final grade, students had the opportunity of applying any points they earned on the pre-course examination toward their lowest grade on any one of the unit tests. Since it is not uncommon for students to obtain a low score on at least one of the unit tests, this incentive was very well received. With regard to the 
pre-course administration of the SBI, the researcher and instructor addressed the students and explained that due to the difficulty that many students have with the course, the college was trying to identify areas in which additional skills or instruction could be provided. The researcher believes that these incentives strongly encouraged the best efforts of the participants on both pre-course tests.

The course instructor was shown proper administration methods for the SBI by the researcher before official data collection commenced to ensure that the students completed the instrument correctly and in its entirety. The completed instruments were collected by the instructor and delivered to the researcher for scoring and recording after each administration.

\section{Subjects}

The sample was composed of students in four sections of Anatomy and Physiology I taught by one instructor who agreed to cooperate in the research. Two classes were randomly designated to serve as the treatment group, which participated in the program of SI and two served as the control group that did not receive Supplemental Instruction, but participated in an alternative activity. There were approximately 40 students in each of these classes. This allowed for statistical tests of differences between adjusted group means of $.5 \sigma$ with a power between .85 and .90 at the $p=.05$ level of significance. The population from which the researcher obtained the sample was comprised of students attending Broward Community College-North Campus who were enrolled in an Anatomy and Physiology I Lecture course. The population is known to encompass a wide age range, and is racially and ethnically diverse. 


\section{SI Leader}

The SI leader in this study was experienced, having acted in this role previously for several semesters. At the time of this study, the two SI supervisors had identified this individual as the best leader currently available. All SI supervisors have attended UMKC Supplemental Instruction supervisor training sessions and receive periodic newsletters from the Supplemental Instruction Center at the University of Missouri at Kansas City.

At the institution that served as the setting of the present study, at the beginning of each semester all SI leaders participate in a $2 \frac{1}{2}$ day training workshop. Even experienced leaders must attend these sessions to reinforce appropriate SI practices. During this training, they receive the UMKC Supplemental Instruction manual, which is used as a resource in the SI sessions with students. It contains examples of various collaborative activities, attendance sheets for SI participants, and planning sheets for each SI session. Using these materials, and two UMKC videos of lectures, two model SI sessions are conducted during this training period. For these mock sessions the SI leaders participate as students and the SI supervisors model the behaviors that the SI leaders are expected to later demonstrate in their own SI sessions. As part of this activity, SI supervisors facilitate leaders' participation in cooperative activities. In addition SI supervisors use examples in the manual to review potential student behavior problems (e.g., complaining about the course instructor) and appropriate SI leader responses.

At the conclusion of the training session, each SI leader is introduced to the course instructor he or she will be working with and receives a course textbook and ancillary materials such as study guides and workbooks. During the course of the semester, an SI supervisor visits an SI session of each SI leader at least once every 2 
weeks and meets with each leader weekly. This training and follow-up procedure were followed during the semester of the present study.

\section{Procedures}

The treatment for the experimental group consisted of student participation in a mandatory SI session (academic support emphasizing collaboration and interaction and led by peer facilitators) following the regular course period. It should be noted that SI participation was originally designed to be and is usually voluntary, but there is some evidence that no significant differences in efficacy have been observed between mandatory and voluntary sessions (Hodges, 2001).

In order to address the question about SI raised by some researchers as to whether or not the double-exposure to course material is the source of the improvement in student achievement and study behaviors, an alternative "placebo" activity was arranged for the control group. The students in the control group received a chapter-specific web-based review provided by the publisher of the course text. Outside of the class, after each chapter was covered, the control group was required to participate in an on-line interactive chapter review. After this review they took an on-line "feedback quiz". The quiz was graded during the session and the students were able to see which questions they missed. The incorrect questions were frequently followed by an explanation of the rationale for the correct choice. The control group students were then required to review the corrected quiz and then go back (via the browser back button), correct the questions they missed, resubmit, and upon receiving $100 \%$ e-mail this completed quiz to the instructor. The students also had the opportunity to print the completed quizzes and use 
them as study notes. Considering the number of chapters the instructor covers during the course, this activity represented a significant portion of the final course grade.

The researcher and instructor acknowledged that $100 \%$ attendance at, and participation in, the mandatory SI for the treatment group and the alternative mandatory web-based review sessions for the control group was an unrealistic expectation. In consideration of this fact, full course credit was obtained by the students in both groups only if they participated in $70 \%$ of their respective study activities.

The treatment consisted of participation in mandatory SI sessions immediately following each regular course period. The sessions were designed to be the same length as the lecture. Since each of the two SI classes met twice a week for 1 hour 15 minutes each time, the SI sessions were also 1 hour 15 minutes each. Using the UMKC Supplemental Instruction manual describing how to facilitate group activities received during pre-semester training, the SI leader prepared materials to be used at each session. After attendance was taken, students typically formed into groups of three or four. They were encouraged to vary who they chose to work with. The groups engaged in varied activities, the content of which was related to material presented in the previous lecture. This arrangement allowed time for the SI leader to prepare appropriately. For example, occasionally the SI leader would bring bones or models to the SI sessions.

In these sessions, individual groups might be asked to explain a particular point or topic to the rest of the group, or to work together to label a diagram or fill in a crossword puzzle, or jointly complete and explain correct answers to practice quizzes. Before, during, and after each activity students were encouraged to ask the SI leader questions. The SI leader was trained to turn the questions back to the entire group so that they might 
work collaboratively and in the end empower themselves as students. The session before each chapter test was designed as a review of course material for the test, while the session following each test was used to go over each test question. In addition to the sessions, students also regularly saw the SI leader in the Anatomy class, arriving on time, taking notes, asking clarifying questions, and generally being a model student. SI participants thus learn about good study behaviors both during class and the SI sessions.

As previously described, the control group did not attend SI sessions following the regular Anatomy and Physiology I course period, nor did they have access to the sessions associated with the sections comprising the treatment group. The control group participated only in the alternative activity. At the beginning and the end of the semester, both groups were administered the same two instruments.

\section{Instrumentation}

Two measures were utilized in this study, on both a pre-test and post-test basis, and the pretreatment scores were used as covariates in the data. First was the Anatomy and Physiology I final exam, a 90-item comprehensive examination which functioned as a measure of achievement. Second was the Study Behavior Inventory (Bliss \& Mueller, 1990), a 46-item measure that stresses assessment of study behaviors (habits) as opposed to study skills.

Anatomy and Physiology I Lecture final examination. The final exam in Anatomy and Physiology I Lecture is a 90-item multiple choice test, administered during the final exam period at the end of each college semester. The examination's questions are formulated by the instructor to measure content mastery as they relate to the learning 
objectives identified by the college curriculum committee. It is cumulative, and although students are given 2 hours to complete it, many finish in less time than this.

The calculation of the final grade in the Anatomy and Physiology I course is based upon four unit tests and a comprehensive final examination. Since the Anatomy and Physiology I unit tests and final course examination are constructed by each individual instructor, and therefore can vary slightly from instructor to instructor, a study of the proposed measure's content validity is warranted. A widely used method for measuring content validity was developed by Lawshe (1975). Essentially, this is a method developed for gauging how essential a given test item was in the realm of employment testing. This method entails raters on an "expert" judging panel being asked to respond after each test item: Is the knowledge measured by this item: (a) essential, (b) useful but not essential, or (c) not necessary to the performance of the job? According to Cohen and Swerdlik (2002), for example, a cumulative final in statistics for example would be content-valid if the type and proportion of problems on the test approximated the type and proportion of problems covered in the course. A like determination was employed to establish the content-validity of the Anatomy and Physiology I final examination that the researcher used in this study.

Topics appropriate for an Anatomy and Physiology I course constitute the domain of interest, and these topics are generally determined from the chapter and section headings of the course's main textbook (Saladin, 2002). An expert committee consisting of three Anatomy and Physiology I instructors from each of three separate campuses of Broward Community College reviewed the final examination and verified the validity of the content. The expert panel evaluated two aspects of each question: (a) the 
appropriateness of the topic the question is testing, and (b) the adequacy of the question in testing that topic. A modified version of the examination was used, where each exam question was followed by the two aspect questions and a Likert scale response format of strongly agree (5) to strongly disagree (1). Each rater responded to both questions regarding the appropriateness of the topic and the adequacy of the question in testing that topic. In this way both content validity and question quality of the final examination are addressed (Kenney, 1989).

In the present study, the results from this process of measuring the content validity of the pre and post test academic examination revealed that the rate of agreement among the judges as to the appropriateness of the questions exceeded $92 \%$ and there was a quality level of 4.3. The latter is the mean of all responses concerning the quality of each test question based on a scale of 1 to 5 (with 5 indicating strong agreement that the item is adequate). Thus the test may be considered content valid.

The Study Behavior Inventory. The Study Behavior Inventory (SBI), developed by Bliss and Mueller $(1987,1990)$, is a 46 -item instrument containing a series of statements requiring subject responses that indicate how frequently a certain statement applies to them. As they appear on the instrument, the specific responses are (1) Rarely or never, (2) Sometimes, (3) Often or usually, (4) Almost always. To avoid response set, the SBI items are framed positively and negatively. Students typically complete the inventory in 15-20 minutes.

Through the application of factor analytic procedures, useful for determining the validity of a measurement instrument (Jackard \& Becker, 1997), three distinct factors were obtained for the SBI. These three factor/groups are further identified as "reasonable 
descriptions of the underlying constructs involved in study behaviors" (Bliss \& Mueller, 1987, p. 15), and "seem to describe categories of behaviors which would commonly be considered to be groups of study behaviors" (Bliss \& Mueller, 1993, p. 51). The instrument evidenced high internal consistency in all factors (Bliss \& Mueller, 1987). Another indication of the construct validity is the high correlations found between SBI scores and GPAs. An examination of the psychometric properties of the SBI (Bliss \& Mueller, 1993), revealed that Cronbach's alpha reliability for the responses to Factors 1, 2 , and 3 , respective reliability estimates were, $86, .82$, and .70 , indicating consistently high levels of internal consistency reliability on the scores on the three factors. Data Analysis

Since this study involved the use of two separate instruments each measuring one of two dependent variables (e.g., content mastery and study behavior), which were projected to exhibit related differences following exposure to the program of Supplemental Instruction, this researcher used an analysis of covariance as the data analysis technique with the pretreatment scores on each of the factors of the Study Behavior Inventory and pretreatment course final examination, as appropriate, as the covariates in each of the ANCOVAs. In testing Hypothesis \#1, the covariate was the pretreatment final examination score. In testing Hypothesis \#2, the covariate was the pretreatment score on the appropriate SBI factor for each of the three ANCOVAs. Thus, a total of four analyses of covariance statistical tests were carried out.

The first analysis tested the hypothesis that the mean final examination score of the students participating in the Supplemental Instruction program, adjusted for their pretreatment achievement test scores, would be higher than the adjusted means of the 
final examination scores of the students who did not participate in the Supplemental Instruction program. The second through fourth analyses tested the hypotheses that the means of the post-treatment scores on each of the three factors of the Study Behavior Inventory of the students participating in the Supplemental Instruction program would be greater than those of the students who did not participate in the SI program when their post-treatment scores SBI are adjusted for their pretreatment SBI scores.

It should also be noted that since with NEGD there is a likelihood of bias in the estimate of treatment effect due to pre-test measurement error and group nonequivalence, which can affect reliability in the ANCOVA model, a reliability-corrected ANCOVA model was used in the statistical analysis of the NEGD to correct for the bias that would occur as a result of measurement error on the pretest. When analyzing data from the nonequivalent group designs it is generally recommended that two analyses be performed; one with an upper-bound estimate of reliability and one with a lower-bound one. Thus, if a significant treatment effect estimate is noted with both analyses, there is a higher level of confidence that a significant effect would have been found in data that had contained no pretest measurement error (Trochim, 2002). The researcher used the SPSS computer program to complete the reliability-corrected ANCOVA.

\section{Summary}

The hypotheses of this study were tested using a non-equivalent group, pretestposttest design. Four classes of students in one semester Anatomy and Physiology I courses taught by the same instructor at a community college were randomly assigned to one of two treatment groups. Two classes received Supplemental Instruction while the 
other two participated, after class time, in a web-based instructional program produced by their textbook publisher. Students in all classes took an achievement test on the content of the Anatomy and Physiology course at the beginning of the semester. They were also administered the Study Behavior Inventory.

During the semester the students in the SI treatment group participated in learner centered activities designed to increase their knowledge of course content and their use of appropriate study behaviors. Sessions were led by SI leaders who had already taken the course and had undergone a training experience in leading SI groups. In order to monitor their compliance with their assignments, students who participated in web-based instruction outside of class were required to turn in quizzes that they took as part of the instruction

At the end of the semester all students again took the Anatomy and Physiology achievement test and the Study Behavior Inventory. The pre-treatment measures were used as covariates and the post-treatment measures were used as independent variables in a series of analyses of covariance to determine if differences existed between students who participated in Supplemental Instruction and those who participated in the webbased treatment in academic achievement and use of appropriate study behaviors. 


\section{CHAPTER IV}

\section{RESULTS}

This results of the study are presented in this chapter. The research investigated the effectiveness of using a program of Supplemental Instruction to increase the frequencies of appropriate study behaviors of students in an Anatomy and Physiology I course in order to increase these students' grades in this gatekeeper course. This chapter contains a description of the sample of participants used in this study and tests of hypotheses concerning the effectiveness of Supplemental Instruction.

\section{Description of the Sample}

The sample of students in the study at the beginning of the semester was 143 with 68 receiving the Supplemental Instruction (SI) treatment and 75 receiving a placebo treatment. At the end of the semester 74 (52\%) of the students were left in the study groups with $39(57 \%)$ of the students in the Supplemental Instruction treatment and 35 $(47 \%)$ of those receiving the control treatment remaining in the sample. Since testing hypotheses required pre- and post-treatment data, this group of 74 students constituted the sample from which data were analyzed. This is a considerable level of participant mortality. While a certain amount of mortality was expected in light of the fact that the study was done in a historically difficult gatekeeper course where attrition is particularly high, this level was somewhat surprising.

\section{The Potential Problems of High Mortality Rates}

The high mortality rate in both groups opens the question of whether mortality was random in nature or was a function of the treatment. If the former were the case, the primary difficulty caused by subject mortality would be the resulting smaller sample sizes 
which would lower the power of statistical tests. If mortality was a function of the treatment, however, then it would have to be assumed that some unaccounted for variable is causing differential mortality in the treatment groups. This confounding variable would need to be identified and controlled or there would be reason to suspect the internal validity of any inferences drawn from the data analysis.

\section{Comparing the Completing and the Non-completing Participants}

To investigate the possibility of differences between the original and final sample, a series of statistical tests were conducted to determine whether there were differences between the participants who completed the course and for whom, therefore, pretreatment and post-treatment data was available and those students who dropped out of the course during the semester for whom only pre-treatment data was available in both the experimental and control groups. These tested differences between the mean achievement test pre-treatment scores of the completing and non-completing participants in both the treatment and control groups, and differences between the mean pretreatment scores on the three SBI factors of the completing and non-completing participants in both the treatment and control groups. Table 1 shows the descriptive statistics for these variables.

Pre-treatment anatomy and physiology content knowledge. A two-way analysis of variance was conducted to test the null hypothesis that the mean score on the pretreatment anatomy and physiology content knowledge examination of the completing participants was equal to the mean score on the examination of the non-completers and to test the interaction between participants' completion status and their group membership. 
Table 1

Descriptive Statistics for Completers and Non-completers on the Achievement Pretest and the Pre-treatment Scores on the Study Behavior Inventory Factors

Non-

Variable

$\begin{array}{ccc}\text { Completers } & & \text { completers } \\ M \quad S D & & S D\end{array}$

\section{Supplemental Instruction Treatment Group}

Academic self-esteem

Time management for the preparation for routine, everyday tasks

Time management for the preparation for long range, unique academic tasks

Anatomy and Physiology achievement test $\begin{array}{llll}41.6 & 7.4 & 39.3 & 6.3\end{array}$

46.4

8.0

$46.6 \quad 7.0$

$\begin{array}{llll}24.6 & 3.8 & 25.3 & 3.2\end{array}$

$\begin{array}{llll}28.1 & 10.7 & 24.7 & 9.3\end{array}$

Placebo Control Group

Academic self-esteem

Time management for the preparation for routine, everyday tasks

Time management for the preparation for long range, unique academic tasks

Anatomy and Physiology I achievement test
42.6

7.9

$39.8 \quad 7.0$

49.4

6.9

$46.2 \quad 7.2$

$25.3 \quad 3.3$

$\begin{array}{llll}26.1 & 10.1 & 25.7 & 7.6\end{array}$

Note. There were 39 completers and 29 non-completers in the SI treatment group. There were 35 completers and 40 non-completers in the placebo control group.

A Levene's test of homogeneity of error variances showed that this ANOVA assumption was valid, $F(3,131)=2.27, p=.08$. There were no significant main effects between completing and non-completing participants and no significant main effects 
between the participants in the treatment group and the control group. Most importantly, there was no significant interaction between completion status and group membership. Table 2 presents the source table for this analysis.

Table 2

Analysis of Variance for Achievement Pretest

\begin{tabular}{lrcrc}
\hline Source & $d f$ & $F$ & $\eta$ & $p$ \\
\hline Treatment (T) & 1 & 0.11 & $<.01$ & .75 \\
Completion (C) & 1 & 1.39 & .01 & .24 \\
$\mathrm{~T} \times \mathrm{C}$ & 1 & 0.92 & .01 & .34 \\
$\quad$ error & 139 & $(89.74)$ & & \\
\hline Note. Values enclosed in parentheses represent mean square errors.
\end{tabular}

Study behaviors. A series of two-way analyses of variance were used to test null hypotheses concerning the equality of the mean scores of the participants who completed the course and those who did not complete on the three factors of the Study Behavior Inventory for both the treatment and control groups. For Factor 1, Academic self-esteem, the Levene's test for homogeneity of error variance showed that this assumption was met, $F(3,131)=.42, p=.74$. There were no significant main effects between completing and non-completing participants and no significant main effects between the participants in the treatment group and the control group. Also, there was no significant interaction between completion status and group membership. Table 3 presents the source table for this analysis

Table 3

\begin{tabular}{lrccc} 
Analysis of Variance for the SBI Factor 1 & Pretest \\
\hline Source & $d f$ & $F$ & $\eta$ & $p$ \\
\hline Treatment (T) & 1 & 0.60 & .01 & .44 \\
Completion (C) & 1 & 3.21 & .02 & .08 \\
T $\times$ C & 1 & $<.01$ & $<.01$ & .96 \\
$\quad$ error & 139 & $(54.53)$ & & \\
\hline
\end{tabular}

Note. Values enclosed in parentheses represent mean square errors. 
For Factor 2, Time management for the preparation for routine, everyday tasks, the Levene's test for homogeneity of error variance showed that this assumption was met, $F(3,131)=.38, p=.77$. There were no significant main effects between completing and non-completing participants and no significant main effects between the participants in the treatment group and the control group. Also, there was no significant interaction between completion status and group membership. Table 4 presents the source table for this analysis.

Table 4 Analysis of Variance for the SBI Factor 2 Pretest

\begin{tabular}{lrccc}
\hline Source & $d f$ & $F$ & $\eta$ & $p$ \\
\hline Treatment $(\mathrm{T})$ & 1 & 1.00 & .01 & .32 \\
Completion $(\mathrm{C})$ & 1 & 1.32 & .01 & .25 \\
$\mathrm{~T} \times \mathrm{C}$ & 1 & 1.76 & .01 & .19 \\
$\quad$ error & 139 & $(54.01)$ & & \\
\hline
\end{tabular}

Note. Values enclosed in parentheses represent mean square errors.

For Factor 3, Time management for the preparation for long range, unique academic tasks, the Levene's test for homogeneity of error variance showed that this assumption was met, $F(3,131)=.71, p=.55$. There were no significant main effects between completing and non-completing participants and no significant main effects between the participants in the treatment group and the control group. In addition there was no significant interaction between completion status and group membership. Table 5 presents the source table for this analysis.

Conclusions about differences between completers and non-completers. There were no significant differences between the means of the scores of completers and noncompleters on the Anatomy and Physiology I pretest or any of the pretest scores of the factors of the Study Behavior Inventory. More important, however, is that there were no 
significant interactions between the treatments and the completion status of the participants on any of the pre-treatment measures. If the withdrawal had been selective with either the more able or less able students more likely to withdraw than other students, there would have been an interaction between these two variables. Hence, it may be concluded that withdrawal from the Anatomy and Physiology I course was not selective and that mortality should have no effect on the internal validity of the inferences drawn from this data.

Table 5

Analysis of Variance for the SBI Factor 3 Pretest

\begin{tabular}{lrcrc}
\hline Source & $d f$ & $F$ & $\eta$ & $p$ \\
\hline Treatment (T) & 1 & 1.17 & .01 & .28 \\
Completion (C) & 1 & $<.01$ & $<.01$ & .95 \\
$\mathrm{~T} \times \mathrm{C}$ & 1 & 1.09 & .01 & .30 \\
$\quad$ error & 139 & $(12.74)$ & & \\
\hline
\end{tabular}

Note: Values enclosed in parentheses represent mean square errors.

\section{Tests of Hypotheses}

Four hypotheses were tested using analysis of covariance. Since proponents of Supplemental Instruction claim that SI increases the frequency of appropriate study behaviors of students (Arendale, 1994), three of these tested hypotheses concerned differences in post-treatment levels of study behaviors by treatment using pre-treatment values of these behaviors as measured by the three factors of the Study Behavior Inventory as covariates. The fourth tested the hypothesis concerning differences in anatomy and physiology content knowledge between these groups using a pre-treatment measure of achievement as a covariate since the literature suggests that increased frequency in the use of appropriate study behaviors will result in higher levels of achievement. 
To test the first hypothesis an analysis of covariance was conducted using the post-treatment scores on the academic self-esteem factor of the Study Behavior Inventory as the dependent variable, treatment group membership as the independent variable, and pre-treatment scores on the academic self-esteem factor of the SBI as the covariate. First, the assumption of homogeneity of slopes was tested by observing the interaction between the independent variable and the covariate and testing the null hypothesis that there was no interaction between these two variables. It was found that there was no significant interaction: $F(1,70)=.13, p>.05$, so it was concluded that the homogeneity of slopes assumption was confirmed for these data. This being so, the ANCOVA described at the beginning of this paragraph was carried out. Table 6 presents the source table.

Table 6

\begin{tabular}{lrccc} 
ANCOVA for the SBI Self-Esteem Factor & \multicolumn{5}{c}{} \\
\hline Source & $d f$ & $F$ & $\eta$ & $p$ \\
\hline Pre-treatment Self-Esteem SBI factor & 1 & $60.75^{*}$ & .46 & $<.001$ \\
Treatment & 1 & $<.01$ & 0.00 & .95 \\
$\quad$ error & 71 & $(40.43)$ & & \\
\hline
\end{tabular}

Note. Values enclosed in parentheses represent mean square errors. ${ }^{*} p<.01$

There was no significant difference between the adjusted mean post-treatment scores of the SI treatment group (adj. $M=43.10$ ) and the control group that received the placebo treatment (adj. $M=43.00$ ) on the self-esteem factor of the Study Behavior Inventory. Hypothesis 2

The second hypothesis was also tested using an analysis of covariance. The posttreatment scores on the time management for the preparation for routine, everyday tasks factor of the Study Behavior Inventory were used as the dependent variable. Treatment 
group membership was the independent variable, and pre-treatment scores on the time management for the preparation for routine, everyday tasks factor of the SBI was the covariate. The assumption of homogeneity of slopes was met: $F(1,70)=.34, p=.56$. Table 7 displays the source table for the test of the null hypothesis that the adjusted mean scores of the SI and placebo groups on the time management for the preparation for routine, everyday tasks factor of the SBI were equal.

Table 7

ANCOVA for the SBI Time Management for the Preparation for Routine, Everyday Tasks Factor

\begin{tabular}{lrccc}
\hline Source & $d f$ & $F$ & $\eta$ & $p$ \\
\hline Pre-treatment Routine Tasks Factor & 1 & $45.08^{*}$ & .39 & $<.001$ \\
Treatment & 1 & .75 & 0.01 & .39 \\
$\quad$ error & 71 & $(30.28)$ & & \\
\hline
\end{tabular}

Note. Values enclosed in parentheses represent mean square errors.

${ }^{*} p<.01$

There was no significant difference between the adjusted mean post-treatment scores of the SI group (adj. $M=48.62$ ) and the control group (adj. $M=47.49$ ) on the time management for the preparation for routine, everyday tasks factor of the SBI. Hypothesis 3

The final hypothesis concerning study behaviors was tested using an analysis of covariance with the post-treatment measure of the time management for the preparation for long range, unique academic tasks factor of the Study Behavior Inventory as the dependent variable. Group membership was the independent variable and the pretreatment measure of the SBI factor as the covariate. The homogeneity of slopes assumption was found to be appropriate: $F(1,70)=.33, p=.57$. This being the case, the null hypothesis of equal adjusted mean scores on the time management for the 
preparation for long range, unique academic tasks factor for the treatment and control groups was tested. Table 8 presents the source table for this ANCOVA.

Table 8

ANCOVA for the SBI Time Management for the Preparation for Long Range, Unique Academic Tasks Factor

\begin{tabular}{lrccc}
\hline Source & $d f$ & $F$ & $\eta$ & $p$ \\
\hline Pre-treatment Long Range Tasks Factor & 1 & $19.78^{*}$ & .22 & $<.001$ \\
Treatment & 1 & .07 & $<.01$ & .79 \\
$\quad$ error & 71 & $(11.90)$ & & \\
\hline $\begin{array}{l}\text { Note. Values enclosed in parentheses represent mean square errors. } \\
p<.01\end{array}$ & & & & \\
$p$ & & &
\end{tabular}

There was no difference between the adjusted mean post-treatment scores of the SI group (adj. $M=76.51)$ and the control group (adj. $M=77.83$ ) on the time management for the preparation for long range, unique academic tasks factor of the SBI.

Anatomy and Physiology I Content Knowledge

The final hypothesis was that students who received Supplemental Instruction would score higher on the class final examination of Anatomy and Physiology I content knowledge than students who did not receive SI. A final analysis of covariance was carried out to test this hypothesis using the post-treatment score on the examination of anatomy and physiology content as the dependent variable, treatment as the independent variable, and the pre-treatment examination score as the covariate. First, the homogeneity of variance assumption was tested and it was found that the assumption was valid: $F(1,70)=.30, p<.01$. Table 9 shows the source table of the ANCOVA for differences by treatments. 
Table 9

ANCOVA for Anatomy and Physiology Content Knowledge

\begin{tabular}{|c|c|c|c|c|}
\hline Source & $d f$ & $F$ & $\eta$ & $p$ \\
\hline Anatomy \& Physiology Examination & 1 & $6.69^{*}$ & .09 & $<.001$ \\
\hline $\begin{array}{l}\text { Treatment } \\
\text { error }\end{array}$ & $\begin{array}{r}1 \\
71\end{array}$ & $\begin{array}{c}.49 \\
(11.90)\end{array}$ & .01 & .49 \\
\hline
\end{tabular}

No significant difference was found on the adjusted means of the anatomy and physiological content knowledge examination between the treatment group $(\operatorname{adj} . M=$ 76.15 ) and the control group (adj. $M=78.23$ ).

\section{Summary}

The mortality rate of participants in this study was a rather high $48 \%$.

Considering that the anatomy and physiology courses were chosen in this study because they were gatekeeper courses where students are traditionally at risk of attrition, some mortality was expected. However, this high a level was surprising. While mortality is not necessary fatal to the internal of inferences drawn from the results of a study, the causes and effects of mortality are important to investigate. If mortality is random it would not be expected to affect the pre-treatment equality of the groups of participants who completed the course and those who did not complete it. Since pre-treatment measures of the dependent variables were used as covariates in ANCOVAs in this study, the issue of group equivalence may not be particularly vital here. However, if participant mortality is not random because of the nature of the treatment, there is likely to be a variable causing this differential mortality that needs to be controlled and the issue of the internal validity of the inferences needs to be examined. So, comparisons between the 61 participants who did not complete the class and the 74 participants who did complete on 
pre-treatment measures of the anatomy and physiology course and the three factors of the Study Behavior Inventory were conducted. These revealed no differences between the completers and non-completers on any of these variables. As a result, it was concluded that participant mortality should not be a problem when considering the internal validity of the inferences from this study.

No significant differences were found between the group of students receiving Supplemental Instruction after each class and those receiving the placebo intervention on any of the three factors of the Study Behavior Inventory. It was concluded that Supplemental Instruction did not increase the frequency of the practice of appropriate study behaviors in these participants. Consistent with this finding, there were no significant differences between the final examination scores of students who received Supplemental Instruction and those who received the control treatment. 


\section{CHAPTER V}

\section{DISCUSSION}

This chapter summarizes the study, presents conclusions based on study results, and discusses implications of the findings and possible directions for future research. The purpose of this study was to test the purported efficacy of the Supplemental Instruction program in increasing academic achievement and the frequency of community college students' use of appropriate study behaviors. In order to increase academic achievement, Supplemental Instruction (SI), a widely-used post-secondary academic assistance program, has a specific focus on the acquisition and application of appropriate study behaviors. The program was initially designed to provide academic assistance for students enrolled in historically difficult post-secondary courses. Based on a review of the literature, Blanc et al. (1983) and later Arendale (1994) claimed that Supplemental Instruction not only assisted students to obtain higher grades and master course content, but additionally facilitated the development and integration of effective study behaviors that were applicable to their later courses.

In the present study, a non-equivalent group, pretest-posttest design was carried out to test two ideas. The first idea was that students enrolled in an Anatomy and Physiology I course who participated in a program of Supplemental Instruction would show higher levels of appropriate study behaviors than those who did not participate in SI. The second idea was that those students who participated in Supplemental Instruction would have higher academic achievement in the Anatomy and Physiology course than those who had no SI experience. The participants were 153 community college students at a single institution enrolled in separate sections of an Anatomy and Physiology I 
course during the fall term of 2004 . There were 128 women and 25 men. Fifty five students were White, 49 Black, 32 Hispanic, and 10 were Asian. Seven of the participants failed to disclose their racial/ethnic category. The age range was 18 to 56 years. Although the mortality rate for participants was quite high, it was determined that there were no differences in the proportions of students in each gender and race/ethnicity group or in the mean ages of the original group of participants and those who remained at the end of the semester.

This study was conducted in four sections of Anatomy and Physiology I taught by the same instructor. Two sections were randomly chosen to serve as the treatment group and students in those sections participated in the program of Supplemental Instruction. Two sections served as the control group, in which students participated in an alternative activity. Both groups were administered pretests and posttests measuring three categories of study behaviors and academic achievement. The results of the data analysis led the researcher to conclude that there were no significant differences between the groups' post-treatment scores on any of the of the study behavior categories or on the content achievement test.

\section{Discussion of the Findings}

As demonstrated in Figure 1, researchers in Supplemental Instruction have long claimed, but never empirically investigated the idea that SI sessions provide students with the opportunity to learn and develop appropriate study behaviors and learning strategies, which result in higher grades (NCSI, 1994, 1997). However, the findings of this study are not consistent with claims that SI helps students develop appropriate study behaviors. Findings of the current study also fail to support the claim that SI increases academic 
achievement. Based on the theoretical path presented in Figure 1, the finding that there were no differences between the Study Behavior Inventory scores of the group of students receiving Supplemental Instruction and those in the control group, was not expected. However, based on the relationship between study behaviors and academic achievement also presented in Figure 1, findings indicated that no achievement differences between the two groups of students should have been expected; and thus, the findings of the study are consistent with that aspect of the model. The researcher feels that there are several possible reasons for these findings.

Fidelity of Treatment

Situations occur in research designs where the treatment is so weak that it could not possibly affect the dependent variable. This phenomenon is often referred to as lack of fidelity of treatment. One possible explanation of the results of this study may be the lack of fidelity of treatment.

Treatment time. One of the longstanding claims of SI proponents is that the students master skills and behaviors that are transferable and applicable to other courses. Being that this study was only conducted over one semester, it is possible that a later and fuller expression of what may in fact be a slower and ongoing development of appropriate study behaviors could manifest beyond the time allotted for this study. Just as an individual experiences difficulty in making permanent changes in unhealthy or less than ideal eating behaviors, permanently altering ingrained study behaviors likely requires an extended period of time. As an example of the former, in one study of behavioral correlates in successful weight reduction and maintenance, results showed that achieving long-term weight reduction involves a "complex process of behavioural 
change" (Westenhoefer, vonFalck, Stellferdt, \& Fintelmann, 2004, p. 335). The authors also found that the minimum therapeutic support period required for effecting such a lasting change is 1 year. It is therefore reasonable to assume that similar attempts at altering study behavior long-term may likewise require a similar length of time, and involve a similarly complex process.

There is another reason why more than one semester of SI may well be necessary to bring about any measurable difference in study behaviors. Research has demonstrated that multiple exposures are necessary for students to embrace a particular learning cycle and self-regulatory behavior (Dunkhase, Hand, Shymansky, \& Yore, 1997; Lindgren \& Bleicher, 2005; Miller \& Brickman, 2004; Ogden et al., 2003; Pape, Bell, \& Yetkin, 2003; Runkle, Osterholm, Hoban, McAdam, \& Tull, 2000). This is especially true when science is the subject in question. A teaching strategy based on constructivist-oriented instruction principles has come to be described as the learning cycle (Lindgren \& Bleicher, 2005). A learning cycle is comprised of clearly delineated phases (Karplus et al., 1977). Over the years these phases have been renamed and the cycle expanded, resulting, for example, in the 5-E model recommended for science instruction. In the 5-E model adopted for the Biological Science Curriculum Study (BSCS) curriculum (Lindgren \& Bleicher, 2005), phases require students to engage, explore, explain, elaborate, and evaluate (Coe, 2001). Such constructivist-based concepts are at the core of the Supplemental Instruction approach.

It has been shown in studies of science education, that inadequate exposure to the new behavior when learning a new strategy often results in students' adopting inappropriate science learning strategies. Failure to embrace the proposed learning cycle 
(and the associated alteration of mindsets) with a single exposure seems to be especially relevant with students who had been successful science students earlier in their academic careers (Lindgren \& Bleicher, 2005). It is quite reasonable to assume that students enrolled in particularly challenging college-level science courses, such as the students enrolled in the Anatomy and Physiology course in this study, have indeed experienced some prior academic success in the area of the sciences. It follows that those students who choose to pursue areas of study in college that emphasize the sciences are encouraged to do so by having done well in their high school level courses. In addition, the majority of student-participants in the present study, were advised to, and then opted to complete a basic college-level chemistry course before enrolling in the more advanced Anatomy and Physiology course.

As Lindgren and Bleicher (2005) have pointed out, science students, in particular, require more than a single exposure to a proposed learning cycle in order to fully embrace said cycle, the learning cycle presented through SI, which not only focuses on content but on modeling successful study behaviors specific to that content, may indeed require several semesters to achieve optimal effectiveness. The current study results revealed no significant differences in study behaviors between the SI group that had undergone the modeling experience and the non-SI students who did not have this experience. If as the literature on student success suggests, one semester is not sufficient time to alter study behaviors, this means in effect that there was no difference in the treatments of the two groups: Both groups had the benefit of double exposure to the content. Therefore, it would follow that there would be no difference in achievement 
between the groups, and the study results support this contention. While the content, designed to be learned in one semester, can indeed be learned in one semester, altering study behaviors through the modeling of effective behaviors (most especially with students having a history of academic success in science in more basic courses), may require multiple, and possibly serial exposures.

Overall, long-term behavioral change has been shown to require multiple exposures to training models. This level of exposure is needed before complete understanding and incorporation into usual practice can be achieved, and although it is commonly accepted that time must be set aside to practice the desired behaviors, the ideal length of time can be difficult to determine (Pape et al., 2003; Runkle et al., 2000).

In addition, researchers have determined that programs focused on improvement in students' motivation and self-regulation are critical to academic success, but must include support for future goals and subgoals to exert a long-term influence on selfregulatory behavior. The difficulty of addressing proximal motivation, self-regulated learning, and future orientation has been recognized, and the need for an expanded intervention voiced (Miller \& Brickman, 2004). It can be seen that the creation of future goals in the student that include school learning as a subgoal must be at the heart of any academic assistance program designed to modify student behavior long-term. Not only is the development of future goals important, but equally important is the added element of having the goals personally valued (Miller \& Brickman, 2004). The students must recognize the existence of the goal, attach some value to it, and have adequate confidence in their ability to overcome difficulties to ultimately attain it. 
As Miller and Brickman (2004) have pointed out, students must experience some academic success as they encounter increasingly advanced courses before they can envision future successful possibilities and the role of school learning in getting there. It is highly likely that more than one semester of any academic assistance program (no matter how effective) is necessary to fully develop the future goal orientation and appreciation and affinity for academics that are the underpinnings of long-term behavioral change.

Beyond this, programs designed to assist students in acquiring additional skills, behaviors and, attributional patterns in order to boost self-efficacy may also need to involve sweeping changes in instructors and their instructional behavior (Miller \& Brickman, 2004). This may be necessary for students to overcome negative outcome expectations associated with academics, and allow for students to acquire cognitive and behavioral skills instrumental to learning success. The importance of an instructor's overt support for the SI program, and the ability of that instructor to acknowledge and recommend SI as a viable solution to academic difficulties, both actual and perceived, cannot be understated. It is very possible that one instructor, over one semester, would not be capable of changing existing expectations of negative outcomes. This could account for the lack of change in SBI Factor 1 scores (measures of academic self-esteem) and to the failure to find post-treatment differences between groups on this factor in this study.

A pattern of academic success as opposed to an isolated incident is a likelier counter to students' beliefs that they lack an inherent ability, and a better way to promote students' reliance on proven skills and behaviors over time. It is likely that several 
successive demonstrations of the effectiveness of recommended study skills and behaviors would provide the necessary reinforcement for such skills and behaviors to be permanently incorporated by the learners. This study only spanned the length of one semester, and therefore, may be premature in attempting to measure a behavioral change that would appear to require multiple exposures over a longer period of time. Adding SI sessions not only for more sections of the "difficult" courses, but also for a broader range of courses in different subject areas would go a long way toward achieving the multiple (and ideally serial) exposures so critical to long-term behavioral change. Concurrent academic success in several subject areas would facilitate the development of a future goal orientation in the student by instilling and reinforcing the all-important confidence in their ability to ultimately attain it.

Involuntary assignment of participants to treatment groups. There is also the issue of self-selection as an indicator of inherent motivation. SI was originally designed to be voluntary. Active involvement in learning, (e.g., demonstrating the motivation and desire to participate) has long been recognized as a critical element for learning. Wood, Bruner, and Ross (1976) referred to this as maintaining the pursuit of the goal, and argued that it is vital to student engagement and ultimate learning. Motivation and support of the learning activities are critical to engagement, and engagement is critical to knowledge acquisition. Freebody (2005) has suggested that the five phases students move through within the process of participation are attention, stimulation, engagement, consistency, and pleasure.

Given the process described by Freebody, it would be foolish to ignore the fact that in the present study motivational elements could have been compromised by the 
enforcement of mandatory participation. Within the process of participation, attention, consistency, and stimulation might have been activated by the possibility of a higher grade, but full engagement and the element of pleasure may have been sacrificed in the present study by requiring one group of students to participate in Supplemental Instruction activities regardless of their level of motivation for doing so.

Looking at motivation to change from a slightly different angle, strategy training depends upon the creation of a learning culture in which the aspects of learning and instruction are openly discussed, and self-regulation strategy is integrated into the day-today study context (Masui \& De Corte, 2005). This integration, not only requires an optimal environment, but also identifiable and demonstrable value, which is recognized and accepted over time. Motivation, not surprisingly, is rooted in the recognition of said value. Those who are motivated to use exemplary strategies and behaviors freely incorporate them, while those who are not so motivated do not (Miller \& Brickman, 2004). It is likely that those students described in the literature who volunteer to become involved in SI activities and subsequently do well in academic courses are those who were already sufficiently motivated to perform at higher levels. There is no reason to suspect that the proportion of such motivated students in the SI group was different from their proportion in the control group. This situation may well account for the lack of differences in achievement between the groups.

\section{Double Exposure}

It has been suggested that the success of Supplemental Instruction, rather than being due to its activities that develop appropriate study and learning behaviors, is simply due to the fact that it provides students with additional exposure to course content. 
Double-exposure to course material, in the simplest terms, is nothing more than additional time on task. It has long been recognized that time-on-task plays a role in academic achievement because how much is learned is tied in part to the time spent in task engagement (Gest \& Gest, 2005). Individual differences in time-on-task often equate directly to differences in new academic skills (Bloom, 1974).

As described earlier, both treatments used in this study involved, to some degree, additional exposure to course materials and concepts. SI sessions, although not structured or intended to be merely a reiteration of information presented in the classroom, nonetheless do require a reconsideration of the material presented. SI proponents insist that the purpose of SI is to develop successful learning strategies and behaviors, and propose that the SI leader models such strategies and behaviors. However, what is generally unacknowledged is that in demonstrating the most effective ways such information should be learned and remembered, the content of the course is secondarily revisited. In addition, the SI sessions always being associated with a particular course (in the case of this study Anatomy and Physiology I) render them by nature content specific. Consequently, the SI program cannot escape the criticism that the improved academic achievement that is the promised and expected outcome of participation in SI sessions is tied, even in part, to the foundational element of additional time-on-task.

Referring again to the model presented in Figure 1, since Supplemental Instruction did not have an effect on the frequency of students' use of appropriate study behaviors in the SI group, it may now be suggested that there was really no difference in the instructional treatments of the two groups of students. Since the control group also 
clearly experienced additional exposure to course content (see Chapter 3), then it appears likely that the lack of difference in the achievement of the two groups was due to the fact both groups had had additional exposure to this course content. Therefore, these findings would seem to lend some support to the contention that the reported success of other SI programs is primarily based upon their providing double-exposure to course material (Kenney, 1989).

Academic Characteristics of Participants

It is also worth noting here that Supplemental Instruction advocates suggest that one of the strengths of SI is that it identifies at-risk courses rather than at-risk students (Martin \& Arendale, 1993). However, SI is used quite extensively with at-risk students in programs of developmental instruction. Studies that show the greatest effect are those done using developmental students. In fact, Ramirez (1997) and Ogden et al. (2003) noted that at-risk students are the greatest beneficiaries of Supplemental Instruction programs. McCarthy et al. (1997) found that, in a mixed sample of regular and developmental students, the at-risk developmental students showed improved academic achievement using SI while the regular students showed no significant improvement. The students in the present study were all regular students taking a regular college course. This could account for the lack of effect noticed in achievement. Sample Size

A final explanation of the "no difference" findings might be related to a $48 \%$ attrition rate in the sample between the beginning of the study and the time it was completed. While it was found that the levels of attrition were equal in experimental and control groups and that the final sample did not differ from the original sample in terms 
of participants' demographic characteristics or pretreatment subject area knowledge, the smaller final sample size may have had some effect on the conclusions drawn from the data in this study. The smaller sample size certainly lowered the power of the statistical tests carried out on the data with the result that the probability of these tests to detect a non-zero effect size was lower than it would have been if data from the original sample had been available. In short, the probability of the results of the statistical tests being due to Type II error was increased and this could affect the validity of inferences made from the data when it was concluded that the null hypothesis could not be rejected. Specifically, differences that actually existed between populations from which the samples were drawn could have gone undetected by the statistical tests.

Conclusions, Implications, and Directions for Future Research

Unlike much supportive empirical research lauding the program of Supplemental Instruction, this study failed to find sufficient evidence to recommend it as it is currently implemented. Some have suggested that perhaps SI should focus on high-risk students as opposed to high-risk courses, which of course would effectively undermine the advantages of their exposure to more advanced peers in a collaborative learning environment. Still, the results of this study may indeed provide some support for this suggestion. In this study it was noted that control group students who experienced multiple exposures to course material through the alternative activity performed on par with SI students. This supports the suggestion that at least for regular students such as the ones in the present study, multiple exposures to course content alone, rather than also needing the presence of more advanced peers may be sufficient to increase learning. The double exposure experienced by the students in the non-SI group was in the form of an 
online, interactive activity, performed in isolation, without the benefit of exposure to any other peers, advanced or otherwise. This could be investigated by replicating this study using a third group of students who neither received Supplemental Instruction nor participated in a content-based alternative experience in addition to regular class work. The students in this third group, therefore, would not have multiple exposures to the course content.

As to the development of more appropriate study behaviors, future researchers might want to examine if such a fundamental concept as multiple exposures over an extended period of time to course content in fact plants the seed for these behaviors. Important questions that remain unanswered include: Are not some success strategies nothing more than rereading and reprocessing texts and notes? What are the motivational elements underlying appropriate study behaviors and how do we encourage them? Is the reported success of SI based upon simple modeling of a student peer's effective study behaviors? Or, is it something else besides the dual effect of double exposure and open peer communication that holds most promise for a heightened awareness and improved performance?

This study has revealed two important things. First, the development of appropriate study behaviors appears to require more than SI, as it is now implemented, can provide. Second, improved academic achievement may be attained through any number of means focused upon repeated exposure to course material. Future researchers will no doubt discover and then discard a host of alternatives. Some of these alternatives will be only marginally useful, others quickly outdated. Yet what is certain is that 
researchers will continue to search for the key that best unlocks the mind of the learner.

They will do this for the future of education, and the future of the world. 


\section{REFERENCES}

Agnew, N. C., Slate, J. R., Jones, C. H., \& Agnew, D. M. (1993). Academic behaviors as a function of academic achievement, locus of control, and motivational orientation. NACTA Journal, 37, 24-27.

American Psychological Association. (1995). Learner-centered psychological principles: Guidelines for the teaching of educational psychology in teacher education programs. [Electronic version]. Retrieved from http://seamonkey.ed.asu.edu/ gene/TEPSIG/apa-principles.html

American Psychological Association. (1997). Learner-centered psychological principles: A framework for school redesign and reform. Washington, DC: Author. Retrieved November 28, 2001, from http://www.apa.org/ed/lcp.html

Arendale, D. (1994). Understanding the Supplemental Instruction model. In D. C. Martin, \& D. Arendale (Eds.), Supplemental Instruction: Increasing achievement and retention (pp. 11-21). San Francisco: Jossey-Bass.

Arendale, D. (1998). Increasing efficiency and effectiveness of learning for freshman students through supplemental instruction. Retrieved from University of Missouri-Kansas City, Center for Academic Development Web site: http://www.umkc.edu/cad/si/sidocs/daeffe98.htm

Arends, R. I. (1994). Learning to teach ( $3^{\text {rd }}$ ed.). New York: McGraw Hill.

Arons, A. B. (1976). Cultivating the capacity for formal reasoning: Objectives and procedures in an introductory physical science course. American Journal of Physics, 44, 834-838.

Astin, A. W. (1983). What matters in college: Four critical years revisited. San Francisco: Jossey Bass.

Astin, A. W. (1987). Competitive or cooperation? Teaching teamwork as a basic skill. Change, 19, 12-19.

$\mathrm{Au}, \mathrm{K} . \mathrm{H}$. (1998). Social constructivism and the school literacy learning of students of diverse backgrounds. Journal of Literacy Research, 30, 297-319.

Azmitia, M. (1988). Peer interaction and problem solving: When are two heads better than one? Child Development, 59, 87-96.

Bailey, P. D., \& Onwuegbuzie, A. J. (2002). The role of study habits in foreign language courses. Assessment \& Evaluation in Higher Education, 27, 463-473. 
Becvar, D. S., \& Becvar, R. J. (1996), Family therapy: A systemic integration (3 ${ }^{\text {rd }}$ ed.), Needham Heights, MA: Allyn \& Bacon.

Bender, D. S. (2001). Effects of study skills programs on the academic behaviors of college students. Journal of College Reading and Learning, 31, 209-216.

Blais, D. M. (1988). Constructivism: A theoretical revolution in teaching. Journal of Developmental Education, 1/(3), 2-7.

Blanc, R. A., DeBuhr, L., \& Martin, D. C. (1983). Breaking the attrition cycle: The effects of Supplemental Instruction on undergraduate performance and attrition. Journal of Higher Education, 54, 80-89.

Bliss, L. B., \& Mueller, R. J. (1987). Assessing study behaviors of college students: Findings from a new instrument. Journal of Developmental Education, 11(2), 1418.

Bliss, L. B., \& Mueller, R. J. (1990). Study Behavior Inventory. Torrance, CA: Andragogy Associates.

Bliss, L. B., \& Mueller, R. J. (1993). An instrument for the assessment of study behaviors of college students. Reading Research and Instruction, 32(4), 46-52.

Bloom, B. S. (1974). Time and learning. American Psychologist, 29, 682-688

Blumenfeld, P. C., Marx, R. W., Soloway, W., \& Krajcik, J. (1996). Learning with peers: From small group cooperation to collaborative communities. Educational Researcher, 25, 37-40.

Bouton, C., \& Garth, R. Y. (1983). Learning in groups. San Francisco: Jossey-Bass.

Boylan, H. R. (1999). Exploring alternatives to remediation. Journal of Developmental Education, 22(3), 2-8.

Bracey, G. W. (1994). Achievement in collaborative learning. Phi Delta Kappan, 76, 254-256.

Brown, A. L. (1994). The advancement of learning. Educational Researcher, 23(8), 412.

Bruer, J. (1995). Classroom problems, school culture, and cognitive research. In K. McGilly (Ed.), Classroom lessons: Integrating cognitive theory and classroom practice (pp. 273-290). Cambridge, MA: MIT Press. 
Burmeister, S. L. (1994). The challenge of Supplemental Instruction: Improving student grades and retention in high risk courses. In M. Maxwell (Ed.), From access to success: A book of readings on college developmental education and learning assistance programs (pp. 209-214). Clearwater, FL: H\&H Publishing Company.

Butcher, J. N., Graham, J. R., Williams, C. L., \& Ben-Porath, Y. S. (1990). Development and use of the MMPI-2 content scales. Minneapolis, MN: University of Minnesota Press.

Cash, R. W., \& Bissel, H. L. (1985, April). Testing Tinto 's model of attrition on the church-related campus. Paper presented at the Annual Forum of the Association for Institutional Research, Portland, OR. (ERIC Document Reproduction Service No. ED259686)

Cauley, K., \& Tyler, B. (1989). The relationship of self-concept to prosocial behavior in children. Early Childhood Research Quarterly, 4, 51-60.

Cesa, T. A. (1980). Undergraduate leavers and persisters at Berkeley: Results of a telephone survey conducted in spring 1979. Based on a speech presented at the Annual Conference of the California Association for Institutional Research $\left(10^{\text {th }}\right)$. (ERIC Document Reproduction Service No. ED187294)

Chaffee, J. (1992). Critical thinking skills: The cornerstone of developmental education. Journal of Developmental Education, 15, 2-4, 6, 8, 39.

Chavajay, P., \& Rogoff, B. (2002). Schooling and traditional collaborative social organization of problem solving by Mayan mothers. Developmental Psychology, $38(1), 55-66$.

Chen, I. (2002). Constructivism. [Electronic version]. Retrieved from: http:/pdts.uh.edu/ ichen/ebook/ET-IT/constr.htm

Chickering, A. W. (1969). Student-faculty relationships: Bedrock for college governance. Project on Student Development in Small Colleges, Plainfield, VT. (ERIC Document Reproduction Service No. ED038910)

Chickering, A. W., \& Gamson, Z. F. (1987). Seven principles for good practice in undergraduate education. AAHE Bulletin, 39, 3-7.

Christie, N. G., \& Dinham, S. M. (1991). Institutional and external influences on social integration in the freshman year. Journal of Higher Education, 62, 412-436. 
Churukian, G. A. (1982, April). Perceived learning in the classroom and teacher-student interpersonal relationships. Paper presented at Teacher Education 80-90 International Seminar, Groningen, Netherlands. (ERIC Document Reproduction Service No. ED 218273)

Coe, M. A. (2001). Inquiry approach: The 5-E learning cycle model. [Electronic version]. Retrieved from: http://faculty.mwsu.edu/west/maryann.coe/coe/inquire/inquiry.htm

Cohen, J. (1990). Statistical power analysis for the behavioral sciences $\left(2^{\text {nd }}\right.$ ed.). New York: Academic Press.

Cohen, P. A. (1981). Student ratings of instruction and student achievement: A metaanalysis of multisection validity studies. Review of Educational Research, 51, 281-309.

Cohen, R. J., \& Swerdlik, M. E. (2002). Psychological testing and assessment: An introduction to tests and measurement ( $5^{\text {th }}$ ed.). Boston: McGraw-Hill.

Cole, M., \& Wertsch, J. V. (2002). Beyond the individual-social antimony in discussions of Piaget and Vygotsky. [Electronic version]. Retrieved from: http://www.massey.ac.nz/ alock//virtual/colevyg.htm

Commander, N. E., Stratton, C. B., Callahan, C. A., \& Smith, B. D. (1996). A learning assistance model for expanding academic support. Journal of Developmental Education, 20(2), 8-10, 12, 14, 16.

Congos, D. H. (2002). How supplemental instruction stacks up against Chickering's 7 principles for good practice in undergraduate education. Research and Teaching in Developmental Education, 19(1), 75-83.

Congos, D. H., Langsam, D. M., \& Schoeps, N. (1997). Supplemental Instruction: A successful approach to learning how to learn college introductory biology. The Journal of Teaching and Learning, 2(1), 2-17.

Conway, J. (1997). Educational technology's effect on models of instruction. [Electronic version]. Retrieved from: http://copland.udel.edu/ jconway/EDST666.htm

Cooper, P. J., Stewart, L. P., \& Gudykunst, W. B. (1982). Relationship with instructor and other variables influencing student evaluations of instruction. Communication Quarterly, 30, 308-315. 
Davidson, N. (1994). Cooperative and collaborative learning: An integrative perspective. In J. S. Thousand, R. A. Villa, \& A. I. Nevin (Eds.), Creativity and collaborative learning (pp. 20-30). Baltimore: Brookes Publishing.

Davis, J. D., \& Young, R. E. (1982). Students and faculty: Classroom and beyond. Plantings, 3, 1-9.

Dimon, M. (1988). Why adjunct courses work. Journal of College Reading and Learning, 21, 33-40.

Dole, J. A., Duffy, G. G., Roehler, L. R., \& Pearson, P. D. (1991). Moving from the old to the new: Research on reading comprehension instruction. Review of Educational Research, 61, 239-264.

Dunkhase, J. A., Hand, B. M., Shymansky, J. A., \& Yore, L. D. (1997, November). The effect of teacher enhancement projects designed to promote interactiveconstructivist teaching strategies in elementary school science on students' perceptions and attitudes. Paper presented at the School Science and Mathematics Conference, Milwaukee, WI. (ERIC Document Reproduction Service No. ED417960)

Edwards, J. E., \& Waters, L. K. (1982). Involvement, ability, performance, and satisfaction as predictors of college attrition. Educational and Psychological Measurement, 42, 1149-1152.

Elliott, T. R., Godshall, F., Shrout, J. R., \& Witty, T. E. (1990). Problem-solving appraisal, self-reported study habits, and performance of academically at-risk college students. Journal of Counseling Psychology, 37, 203-207.

Feldman, K. A. (1976). The superior college teacher from the students' view. Research in Higher Education, 5, 243-288.

Feldman, R. S. (1983, August). Personality factors and expectation effects in teacherstudent interaction. Paper presented at the Annual Convention of the American Psychological Association, Anaheim, CA. (ERIC Document Reproduction Service No. ED 239184)

Fischer, G. B. (1999). Developing students' adaptive learning skills. College Teaching, $47(3), 96-101$.

Freebody, P. (2005). Literacy teaching practice: Participation. Australian Journal of Language \& Literacy, 28, 195-202. 
Fuchs, L. S., Fuchs, D., Bentz, J., Phillips, N. B., \& Hamlett, C. L. (1994). The nature of student interactions during peer tutoring with and without prior training and experience. American Educational Research Journal, 31, 75-103.

Gamson, Z. F. (1994). Collaborative learning comes of age. Change, 26, 44-49.

Gardiner, L. F. (1994). Redesigning higher education. Producing dramatic gains in student learning. ERIC Digest. ERIC Clearinghouse on Higher Education, Washington, DC; George Washington Univ., Washington, DC; Graduate School of Education and Human Development. (ERIC Document Reproduction Service No. ED394441)

Gauvain, M., \& Rogoff, B. (1989). Collaborative problem solving and children's planning skills. Developmental Psychology, 25, 139-151.

Gersten, R. (1998). Recent advances in instructional research for students with learning disabilities: An overview. Learning Disabilities Research \& Practice, 13, 162170 .

Gest, S. D., \& Gest, J. M. (2005). Reading tutoring for student at academic and behavioral risk: Effects on time-on-task in the classroom. Education and Treatment of Children, 28(1), 25-47.

Gettinger, M., \& Seibert, J. K. (2002). Contributions of study skills to academic competence. School Psychology Review, 31, 350-365.

Goals 2000: Educate America Act, 140 U.S.C. $\S 1804,(1994)$.

Goldschmid, B., \& Goldschmid, M. (1976). Peer teaching in higher education: A review. Higher Education, 5, 9-33.

Greeno, J. G., Collins, A. \& Resnick, L. B. (1996). Cognition and learning. In R. Calfee \& D. Berliner (Eds.), Handbook of educational psychology (pp. 15-46). New York: Macmillan Library Reference.

Henley, M., Ramsey, R. S., \& Algozzine, R. F. (1996). Characteristics and strategies for teaching students with mild disabilities $\left(2^{\text {nd }}\right.$ ed. $)$. Boston: Allyn \& Bacon.

Hodges, R. (2001). Encouraging high-risk student participation in tutoring and supplemental instruction. Journal of Developmental Education, 24(3), 2-9.

Hoover, J. J., \& Patton, P. R. (1995). Teaching students with learning problems to use study skills: A teacher's guide. Austin, TX: Pro-Ed.

Inhelder, B., \& Piaget, J. (1958). Growth of logical thinking. New York: Basic Books. 
Irandoust, M., \& Karlsson, N. (2002). Impact of preferences, curriculum, and learning strategies on academic success. Education Economics, 10(1), 41-48.

Jacobs, L. C., Brigman, S. L., \& Friedman, C. B. (1982). Nonreturning university students: Who are they and why did they leave? Indiana Studies in Higher Education No. 47. (ERIC Document Reproduction Service No. ED217764)

Jackard, J., \& Becker, M. A. (1997). Statistics for the behavioral sciences, $\left(3^{\text {rd }}\right.$ ed.). Pacific Grove, CA: Brooks/Cole.

Johnson, D. W., \& Johnson, R. T. (1989). Cooperation and competition: Theory and research. Edina, $\mathrm{MN}$ : Interaction.

Johnson, D. W., Johnson, R. T., \& Smith, K. A. (1991). Cooperative learning: Increasing college faculty instructional productivity (ASHE-ERIC Higher Education Report No. 4). Washington, DC: George Washington University, School of Education and Human Development. (ERIC Document Reproduction Service No. ED 343465)

Johnson, G. M., \& Buck, G. H. (1995). Students' personal and academic attributions of university withdrawal. Canadian Journal of Higher Education, 25(2), 53-77.

Jones, C. H., Green, A. E., Mahan, K. D., \& Slate, J. R. (1993). College students' learning styles, academic achievement, and study behaviors. Louisiana Education Research Journal, 19, 40-48.

Jones, C. H., Slate, J. R., \& Kyle, A. (1992). Study skills of teacher education students. Teacher Education, 28(1), 7-15.

Jones, C. H., Slate, J. R., \& Marini, I. (1995). Locus of control, social interdependence, academic preparation, age, study time, and the study skills of college students. Research in the Schools, 2, 55-62.

Jones, C. H., Slate, J. R., Perez, E., \& Marini, I. (1996). Graduate students' study skills as a function of academic achievement, sex, conceptions of intelligence, and locus of control. New Directions for Education Reform, 3, 61-78.

Kachgal, M. M., Hansen, L. S., \& Nutter, K. J. (2001). Academic procrastination prevention/intervention: Strategies and recommendations. Journal of Developmental Education, 25(1), 14-24.

Karplus, R., Lawson, A.E, Wollman, W., Appel, M., Bemoff, R., Howe, A., et al. (1977). Science teaching and the development of reasoning. Journal of Research in Science Teaching, 14(2), 169-175. 
Keller, M. J. (1979). Factors related to withdrawal of students from Miami University: Survey Report. (ERIC Document Reproduction Service No. ED179176)

Kenney, P. (1989). Effects of Supplemental Instruction (SI) on student performance in a college level mathematics course (Doctoral dissertation, The University of Texas at Austin, 1988). Dissertation Abstracts International, 50(2), 378A.

Kiewra, K. A. (1988). Cognitive aspects of autonomous note-taking: Control processes, learning strategies, and prior knowledge. Educational Psychologist, 23(2), 39-56.

King, A. (1990). Enhancing peer interaction and learning in the classroom through reciprocal questioning. American Educational Research Journal, 27, 664-687.

King, A. (2002). Structuring peer interaction to promote high-level cognitive processing. Theory into Practice, 41(1), 33-39.

King, J. R., \& Stahl, N. A. (1985). Training and evaluating notetaking. College Reading and Learning Assistance Technical Report 85-06. Georgia State Univ., Atlanta. Div. of Developmental Studies. (ERIC Document Reproduction Service No. ED263537)

Kozulin, A., \& Presseisen, B. Z. (1995). Mediated learning experience and psychological tolls: Vygotsky's and Feuerstein's perspectives in a study of student learning. Educational Psychologist, 30(2), 67-75.

Kucan, L., \& Beck, I. (1997). Thinking aloud and reading comprehension research: Inquiry instruction, and social interaction. Review of Educational Research, 67, 271-299.

Kuhn, D., Black, J., Keselman, A., \& Kaplan, D. (2000). The development of cognitive skills to support inquiry learning. Cognition \& Instruction, 18, 495-523.

Lammers, W. J., Onwuegbuzie, A. J., \& Slate, J. R. (2001). Academic success as a function of the sex, class, age, study habits, and employment of college students. Research in the Schools, 8(2), 71-81.

Lamport, M. A. (1993). Student-faculty informal interaction and the effect on college student outcomes: A review of the literature. Adolescence, 28,971-990.

Lawshe, C. H. (1975). A quantitative approach to content validity. Personnel Psychology, 28, 563-575.

Ley, K., \& Young, D. B. (1998). Self-regulation behaviors in underprepared (developmental) and regular admission college students. Contemporary Educational Psychology, 23, 42-64. 
Light, R. J. (1990). The Harvard assessment seminars: Explorations with students and faculty about teaching, learning, and student life. Cambridge, MA: Harvard University.

Lindgren, J., \& Bleicher, R. E. (2005). Learning the learning cycle: The differential effect on elementary preservice teachers. School Science and Mathematics, 105(2), 6172 .

Lockie, N. M., \& Van Lanen, R. J. (1991). Supplemental Instruction for college chemistry courses. In D. C. Martin, \& D. Arendale (Eds.), Supplemental Instruction: Increasing achievement and retention (pp. 63-74). San Francisco: Jossey-Bass.

Lorch, R. F., Lorch, E. P., Ritchey, K., McGovern, L., \& Coleman, D. (2001). Effects of headings on text summarization. Contemporary Educational Psychology, 26, 171191.

Lundeberg, M. A. (1990). Supplemental Instruction in chemistry. Journal of Research in Science Teaching, 27, 145-155.

Lundeberg, M. A., \& Moch, S. D. (1995). Influence of social interaction on cognition: Connected learning in science. Journal of Higher Education, 66, 312-335.

Lyle, S. (2000). Narrative understanding: Developing a theoretical context for understanding how children make meaning in classroom settings. Journal of Curriculum Studies, 32(1), 45-54.

Marsh, H. W. (1984). Students' evaluation of teaching: Dimensionality, reliability, validity, potential biases, and utility. Journal of Educational Psychology, 76, 707-754.

Marsh, H. W. (1990). Influences of internal and external frames of reference on the formation of math and English self-concepts. Journal of Educational Psychology, $82,107-116$.

Martin, D. C., \& Arendale, D. A. (1993). Supplemental Instruction: Improving first-year student success in high risk courses. Columbia, SC: National Resource Center for the Freshman Experience and Students in Transition. (ERIC Document Reproduction Service No. ED 354839)

Martin, D. C., \& Blanc, R. A. (1994). Video-based Supplemental Instruction: A pathway to mastery and persistence. In D. C. Martin, \& D. Arendale (Eds.), Supplemental Instruction: Increasing achievement and retention (pp. 83-92). San Francisco: Jossey-Bass. 
Martin, D. C., Blanc, R. A, \& Arendale, D. A. (1996). Supplemental Instruction: Supporting the classroom experience. In J. N. Hankin (Ed.), The community college: Opportunity and access for the America's first-year students (pp. 123133). Columbia, SC: The National Resource Center for the Freshman Year Experience and Student Transition. (ERIC Document Reproduction Service No. ED 393486)

Martin, D. C., Blanc, R. A., \& DeBuhr, L. (1983). Breaking the attrition cycle: The effects of Supplemental Instruction on undergraduate performance and attrition. Journal of Higher Education, 54(1), 80-89.

Martin, D. C., Lorton, M., Blanc, R. A., \& Evans, C. (1977). The learning center: A comprehensive model for colleges and universities. Grand Rapids, MI: Aquinas College. (ERIC Document Reproduction Service No. ED 162294)

Masui, C., \& De Corte, E. (2005). Learning to reflect and to attribute constructively as basic components of self-regulated learning. British Journal of Educational Psychology, 75, 351-372.

Maxwell, M. (1990). Does tutoring help? A look at the literature. Review of Research in Developmental Education, 7(4), 1-5.

Maxwell, W. (1998). Supplemental Instruction, learning communities, and students studying together. Community College Review, 26(2), 1-18.

McCarthy, A., Smuts, B., \& Cosser, M. (1997). Assessing the effectiveness of Supplemental Instruction: A critique and a case study. Studies in Higher Education, 22, 221-232.

McKeachie, W. J., Pintrich, P. R., Lin, Y., \& Smith, D. (1986). Teaching and learning in the college classroom: A review of the research literature. Ann Arbor, MI: University of Michigan, National Center for Research to Improve Postsecondary Teaching and Learning.

McMillin, J. (1983). Adapting Supplemental Instruction to English composition classes. In D. C. Martin (Ed.), Supplemental Instruction: A model for student academic support (pp. 95-100). Kansas City, MO: The University of Missouri-Kansas City and the ACT National Center for the Advancement of Educational Practices.

Metcalfe, B. (1981). Self-concept and attitude toward school. British Journal of Educational Psychology, 51, 66-76.

Miller, R. B., \& Brickman, S. J. (2004). A model of future-oriented motivation and selfregulation. Educational Psychology Review, 16(1), 9-33. 
Murray, F. B. (1994). Why understanding the theoretical basis of cooperative learning enhances teaching success. In J. S. Thousand, R. A. Villa, \& A. I. Nevin (Eds.), Creativity and collaborative learning (pp. 1-11). Baltimore: Brookes.

National Center for Supplemental Instruction (1997). Review of research concerning the effectiveness of SI from the University of Missouri-Kansas City and other institutions. University of Missouri-Kansas City.

National Commission on Excellence in Education. (1983). A nation at risk: The imperative for educational reform. Washington, DC: U.S. Government Printing Office.

Newman, P. R., \& Newman, B. M. (1978). Identity formation and the college experience. Adolescence, 13, 311-326.

Nicaise, M., \& Gettinger, M. (1995). Fostering reading comprehension in college students. Reading Psychology, 16, 283-337.

Noel, L., \& Levitz, R. (1982). How to succeed with academically underprepared students: A catalog of successful practices. American College Testing Program, Iowa City, IA. National Center for the Advancement of Educational Practices. (ERIC Document Reproduction Service No. ED227804)

Noel, L., Levitz, R., \& Saluri, D. (1985). Increasing student retention: Effective programs and practices for reducing the dropout rate. San Francisco: JosseyBass.

Ogden, P., Thompson, D., Russell, A., \& Simons, C. (2003). Supplemental Instruction: Short and long-term impact. Journal of Developmental Education, 26(3), 2-8.

Onwuegbuzie, A. J., Slate, J. R., \& Schwartz, R. A. (2001). Role of study skills in graduate-level educational research courses. Journal of Educational Research, 94, 238-247.

Pape, S. J., Bell, C. V., \& Yetkin, I. E. (2003). Developing mathematical thinking and self-regulated learning: A teaching experiment in a seventh-grade mathematics classroom. Educational Studies in Mathematics, 53, 179-202.

Paris, S. G., \& Winograd, P. (1990). Promoting metacognition and motivation of exceptional children. Remedial and Special Education, 11(6), 7-15.

Pascarella, E. T. (1980). Student-faculty informal contact and college outcomes. Review of Educational Research, 50, 545-595. 
Pascarella, E. T., \& Terenzini, P. T. (1976). Informal interaction with faculty and freshman ratings of academic and nonacademic experience of college. Journal of Educational Research, 70, 35-41.

Pascarella, E. T., \& Terenzini, P. T. (1978). Student-faculty informal relationships and freshman year educational outcomes. Journal of Educational Research, 71, 183189.

Peel, E. A. (1972). The nature of adolescent judgment. London: Staples.

Piaget, J. (1954). Construction of reality in the child. London: Routledge \& Kegan.

Piaget, J., \& Inhelder, B. (1969). The psychology of the child. C. Gatlegno \& F. M. Hodgson, Eds/Trans. New York: Basic Books.

Phye, G. D. (1997). Handbook of academic learning: Construction of knowledge. San Diego: Academic Press.

Radziszewska, B., \& Rogoff, B. (1991). Children's guided participation in planning imaginary errands with skilled adult or peer partners. Developmental Psychology, 27, 381-389.

Ramirez, G. M. (1997). Supplemental Instruction: The long-term impact. Journal of Developmental Education, 21(1), 2-9.

Rapmund, V., \& Moore, C. (2002). Enhancing learners' personal resources through narrative: Embracing diversity. South African Journal of Psychology, 32(4), 2233.

Reynolds, W. M. (1994). Self-esteem and classroom behavior in elementary school children. Psychology in Schools, 17, 273-277.

Rodney, E. (1981, April). First-quarter academic performance. Indicators as predictors of college attrition: A study of the 1976-1980 class of Central State University. Paper presented at the Annual Meeting of the American Educational Research Association, Montreal, Canada. (ERIC Document Reproduction Service No. ED230153)

Rogers, C. R. (1962). The interpersonal relationship: The core of guidance. Harvard Educational Review, 32, 416-429.

Runkle, C., Osterholm, A., Hoban, R., McAdam, E., \& Tull, R. (2000). Brief negotiation program for promoting behavior change: The Kaiser Permanente approach to continuing professional development. Education for Health, 13, 377-386. 
Saladin, K. S. (2002). Anatomy and physiology ( $3^{\text {rd }}$ ed.). Boston: McGraw-Hill.

Sandberg, K. E. (1988). Affective and cognitive features of collaborative learning. In Boylan, H. R., \& Kerstiens, G. (Eds.), Models and foundations of developmental education. Review of Research in Developmental Education, 6(1). (ERIC Document Reproduction Service No. ED 341432)

Sandler, M. E. (2000, April). A focal examination of integration, commitment, and academic performance: Three subsystems from the integrated model of student persistence with sociostructural background variable effects. Paper presented at the Annual Meeting of the American Educational Research Association, New Orleans, LA. (ERIC Document Reproduction Service No. ED440277)

Schaie, K. W. (1977). Toward a stage theory of adult cognitive development. International Joumal of Aging \& Human Development, 8(2), 129-138.

Shayer, M., Kuchemann, D. E., \& Wylan, H. (1976) The distribution of Piagetian stages of thinking in British middle and secondary school children. British Journal of Educational Psychology, 48, 62-70.

Simpson, M. L., Hynd, C. R., \& Nist, S. L. (1997). College academic assistance programs and practices. Educational Psychology Review, 9, 39-87.

Sink, C. A. (2002). In search of the profession's finest hour: A critique of four views of 21 st century school counseling. Professional School Counseling, 5, 156-163.

Slate, J. R., Jones, C. H., \& Harlan, E. J. (1998). Study skills of students at a postsecondary vocational-technical institute. Journal of Industrial Teacher Education, $35(2), 57-70$.

Smith, L. S., \& MacGregor, J. T. (1992). What is collaborative learning? In A. Goodsell and others (Eds.), Collaborative learning: A sourcebook for higher education (pp. 131-149). University Park, PA: National Center on Post Secondary Teaching and Learning Assessment.

Somers, R. L. (1988). Causes of marginal performance by developmental students: Telementoring project study guide number six. Boone, NC: Appalachian State University, National Center for Developmental Education. (ERIC Document Reproduction Service No. ED306993)

Spann, N. G. (1990). Student retention: An interview with Vincent Tinto. Joumal of Developmental Education, 14(1), 18-20, 22, 24. 
Stage, F., Mullen, P., Kinzie, J., \& Simmons, A. (1998). Creating learning-centered classrooms: What does learning theory have to say? (ASHE-ERIC Higher Education Report Vol. 26, No. 4). Washington, DC: George Washington University.

Stanley, B., Slate, J. R., \& Jones, C. H. (1999). Study behaviors of college preparatory and honors students in the ninth grade. High School Journal, 82, 165-172.

Strichart, S. S., Mangrum, C. T., \& Iannuzzi, P. (1998). Teaching study skills to students with learning disabilities, attention deficit disorders, or special needs ( $2^{\text {nd }}$ ed.). Boston: Allyn \& Bacon.

Sutherland, P. (1982) An expansion of Peel' s describer-explainer stage theory. Educational Review, 34(1), 69-76.

Sutherland, P. (1999). The application of Piagetian and Neo-Piagetian ideas to further and higher education. International Journal of Lifelong Education, 18, 286-295.

Svinicki, M. D. (1991). Practical implications of cognitive theories. New Directions for Teaching and Learning, 45(2), 27-37.

Tappan, M. B. (1998). Sociocultural psychology and caring pedagogy: Exploring Vygotsky's "Hidden curriculum." Educational Psychologist, 33, 23-34.

Terenzini, P. T., \& Pascarella, E. T. (1980). Student-faculty relationships and freshman year educational outcomes: A further investigation. Journal of College Student Personnel, 21, 521-528.

Theophilides, C., \& Terenzini, P. T. (1981). The relation between nonclassroom contact with faculty and students' perceptions of their academic skill development during college. Research in Higher Education, 15, 255-269.

Thomas, J.W., Bol, L., \& Warkentin, R.W. (1991). Antecedents of college students" study deficiencies: The relationship between course features and students' study activities. Higher Education, 22, 275-296.

Thompson, J., Licklider, B., \& Jungst, S. (2003). Learner-centered teaching postsecondary strategies that promote "thinking like a professional." Theory into Practice, 42, 133-142.

Tinto, V. (1993). Leaving college: Rethinking the causes and cures of student attrition $\left(2^{\text {nd }}\right.$ ed.). Chicago: University of Chicago Press.

Tinto, V. (1997). Classrooms as communities: Exploring the educational character of student persistence. Journal of Higher Education, 68, 599-623. 
Tinto, V. (1998). Colleges as communities: Taking research on student persistence seriously. Review of Higher Education, 21, 167-177.

Tobias, S. (1992). Science education reform: What's wrong with the process? Change, 24(3), $13-19$.

Toma, C., \& Rogoff, B. (1997). Shared thinking: Cultural and institutional variations. Discourse Processes, 23, 471-498.

Tomlinson, L. M. (1989). Postsecondary developmental programs: A traditional agenda with new imperatives. (ASHE-ERIC Higher Education Report No. 3.)

Washington, DC: Association for Study of Higher Education. (ERIC Document Reproduction Service No. ED 316076 )

Trochim, W. K. (2002). Research methods knowledge base. [Electronic version]. Retrieved from: http:/trochim.human.cornell.edu/kb/

Tudge, J. R. H., Winterhoff, P. A., \& Hogan, D. M. (1996). The cognitive consequences of collaborative problem solving with and without feedback. Child Development, $67,2892-2909$.

van Boxtel, C., van der Linden, J, Kanselaar, G. (2000). Collaborative learning tasks and the elaboration of conceptual knowledge. Learning and Instruction, 10, 311-330.

Van Lanen, R. J., \& Lockie, N. M. (1997). Using Supplemental Instruction to assist nursing students in chemistry: A mentoring program's support network protects high-risk students at Saint Xavier University. Journal of College Science Teaching, 26, 419-423.

Vermunt, J. D. (1998). The regulation of constructive learning processes. British Journal of Educational Psychology, 68, 149-171.

Vidal-Abarca, E., Martínez, G., \& Gilabert, R. (2000). Two procedures to improve instructional text: Effects on memory and learning. Journal of Educational Psychology, 92, 107-117.

von Glaserfeld, E., \& Kelley, M. F. (1982). On the concepts of period, phase, stage, and level. Human Development, 25, 152-160.

Vygotsky, L. S. (1962). Thought and language. Cambridge, MA: Harvard University Press.

Vygotsky, L. S. (1978). Mind in society. Cambridge, MA: Harvard University Press. 
Wade, S. E., Trathen, W., \& Schraw, G. (1990). An analysis of spontaneous study strategies. Reading Research Quarterly, 25, 148-166.

Waldron, N. L., \& McLeskey, J. (2000). Preventing academic failure. In K. M. Minke \& G. C. Bear (Eds.), Preventing school problems-promoting school success: Strategies and programs that work (pp. 171-209). Bethesda, MD: National Association of School Psychologists.

Ward, S. L., Byrnes, J. P., \& Overton, W. F. (1990). Organization of knowledge and conditional reasoning. Journal of Educational Psychology. 82, 832-837.

Webb, N. M., \& Palincsar, A. S. (1996). Group processes in the classroom. In D.C. Berlimer \& R. Calfee (Eds.), Handbook of educational psychology (pp. 841-873). New York: Macmillan.

Westenhoefer, J., von Falck, B., Stellfeldt, A., \& Fintelmann, S. (2004). Behavioural correlates of successful weight reduction over $3 y$ : Results from the Lean Habits Study. International Journal of Obesity, 28, 334-335.

Whitman, N. A. (1988). To teach is to learn twice. ASHE-ERIC Higher Education Report No.4. Washington, D. C.: Association for the Study of Higher Education. (ERIC Document Reproduction Service No. ED 305016)

Wilson, B. G. (1995). Metaphors for instruction: Why we talk about learning environments. Educational Technology, 35, 25-30.

Wolfe, R. (1987). The supplemental instruction program: Developing learning and thinking skills. Journal of Reading, 31, 228-232.

Wood, D., Bruner, J. S., \& Ross. G. (1976). The role of tutoring in problem solving. Journal of Child Psychology \& Psychiatry \& Allied Disciplines, 17(2), 89-100.

Woolfolk, A. (2004). Educational psychology $\left(9^{\text {th }}\right.$ ed.). Boston: Pearson.

Wratcher, M.A. (1991). Freshman academic adjustment at a competitive university. College Student Journal, 25, 170-177.

Young, J. R. (2002). Homework? What homework? Chronicle of Higher Education, $49(15)$, A35-A38. 
VITA

\section{EILEEN GARCIA}

Born, Caracas, Venezuela

1984

B.S. Biological Sciences

Florida Atlantic University

Boca Raton, Florida

1990

M.S. Biological Sciences

Florida Atlantic University

Boca Raton, Florida

1990-1994

Biological Sciences Laboratory Manager

Broward Community College

Coconut Creek, Florida

1994-2002

Assistant Professor

Broward Community College

Coconut Creek, Florida

2002-2006

Associate Dean

Broward Community College

Coconut Creek, Florida 